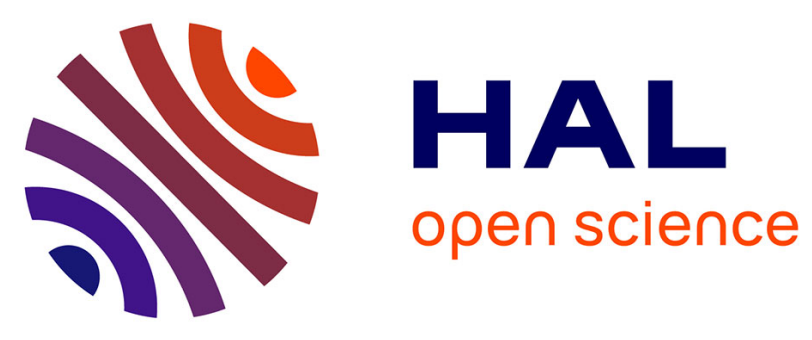

\title{
Exploring Phosphine Electronic Effects on Molybdenum Complexes: A Combined Photoelectron Spectroscopy and Energy Decomposition Analysis Study
}

Héloïse Dossmann, David Gatineau, Hervé Clavier, Antony Memboeuf, Denis Lesage, Yves Gimbert

\section{To cite this version:}

Héloïse Dossmann, David Gatineau, Hervé Clavier, Antony Memboeuf, Denis Lesage, et al.. Exploring Phosphine Electronic Effects on Molybdenum Complexes: A Combined Photoelectron Spectroscopy and Energy Decomposition Analysis Study. Journal of Physical Chemistry A, 2020, 124 (42), pp.87538765. 10.1021/acs.jpca.0c06746 . hal-02997117v2

\section{HAL Id: hal-02997117 \\ https://hal.science/hal-02997117v2}

Submitted on 10 Feb 2021

HAL is a multi-disciplinary open access archive for the deposit and dissemination of scientific research documents, whether they are published or not. The documents may come from teaching and research institutions in France or abroad, or from public or private research centers.
L'archive ouverte pluridisciplinaire HAL, est destinée au dépôt et à la diffusion de documents scientifiques de niveau recherche, publiés ou non, émanant des établissements d'enseignement et de recherche français ou étrangers, des laboratoires publics ou privés. 


\title{
Exploring Phosphine Electronic Effects on
}

\author{
Molybdenum Complexes: A Combined
}

\section{Photoelectron Spectroscopy and Energy}

\section{Decomposition Analysis Study}

H. Dossmann, ${ }^{a *}$ D. Gatineau, ${ }^{a, b \S}$ H. Clavier, ${ }^{c}$ A. Memboeuf, ${ }^{d}$ D. Lesage ${ }^{a}$ and Y. Gimbert ${ }^{a}$

${ }^{a}$ Sorbonne Université, CNRS, Institut Parisien de Chimie Moléculaire, IPCM, 75005 Paris, France.

${ }^{\mathrm{b}}\left({ }^{\S}\right.$ current address) Univ Grenoble Alpes, CNRS, DCM, 38000 Grenoble, France.

${ }^{c}$ Aix Marseille Univ, CNRS, Centrale Marseille, iSm2, Marseille, France.

${ }^{\mathrm{d}}$ Univ Bretagne Occidentale and CNRS, CEMCA (UMR 6521), 29238 Brest, France.

*heloise.dossmann@sorbonne-universite.fr

ABSTRACT. In organometallic chemistry, and especially in the catalysis area, accessing the finest tuning of a catalytic reaction pathway requires a detailed knowledge of the steric and electronic influence of the ligands bound to the metal center. Usually, the M-L bond between a ligand and a metal is depicted by the Dewar-Chatt-Duncanson model involving two opposite interactions, a $\sigma$ donor and a $\pi$-acceptor effect of the ligand. The experimental evaluation of these effects is essential and complementary to in-depth theoretical approaches that are able to provide a detailed description of the M-L bond. In this work, we present a study of $\mathrm{LMo}(\mathrm{CO})_{5}$ complexes with $\mathrm{L}$ being various tertiary phosphines ligands by means of mass-selected high-resolution photoelectron 
spectroscopy (PES) performed with synchrotron radiation, DFT and energy decomposition analyses (EDA) combined with the natural orbitals for chemical valence (NOCV) analysis. These methods enable a separated access of the $\sigma$-donor and $\pi$-acceptor effects of ligands by probing either the electronic configuration of the complex (PES) or the interaction of the ligand with the metal (EDA). Three series of $\mathrm{PX}_{3}$ ligands with various electronic influence are investigated: the strong donating alkyl substituents $\left(\mathrm{PMe}_{3}, \mathrm{PEt}_{3}\right.$ and $\left.\mathrm{P} \mathrm{Pr}_{3}\right)$, the intermediate $\mathrm{PPh}_{\mathrm{x}} \mathrm{Me}_{(3-\mathrm{x})}(\mathrm{x}=0-3)$ set and the $\mathrm{PPh}_{\mathrm{x}} \mathrm{Pyrl}_{(3-\mathrm{x})}$ set ( $\mathrm{x}=0-3$ with Pyrl being the strong electron withdrawing pyrrolyl group $\mathrm{C}_{4} \mathrm{H}_{4} \mathrm{~N}$ ). For each complex, their adiabatic and vertical ionization energies (IEs) could be determined with a $0.03 \mathrm{eV}$ precision. Experiment and theory show an excellent agreement, either for the IEs determination or for the electronic effect analysis. The ability to interpret the spectra is shown to depend on the character of the ligand. "Innocent" ligands provide the spectra the most straightforward to analyze whereas the "non-innocent" ligands (which are ionized prior to the metal center) render the analysis more difficult due to an increased number of molecular orbitals in the energy range considered. A very good linear correlation is finally found between the measured adiabatic ionization energies and the interaction energy term obtained by EDA for each of these two types of ligands which opens interesting perspective for the prediction of ligand characters.

\section{Introduction}

Nowadays, homogeneous organometallic catalysis has become a major tool in both academic and industrial fields. By surrounding the reactive metallic center, ligands play a crucial role through their electronic and steric properties. ${ }^{1}$ They are indeed able to influence the net electron density on the metallic center and can therefore drive its behavior and reactivity. Custom-made ligands may thus lead to high selectivity in chemical transformation. ${ }^{2}$ To access the finest tuning 
of the catalytic reaction pathway, a detailed knowledge of the electronic influence of the ligands is required. Over the years, groundbreaking developments in theoretical and experimental approaches have made possible the increasing knowledge in transition metal coordination chemistry, including the effects of the ligands surrounding the metal center. The electronic interaction between a ligand $\mathrm{L}$ and a metal resulting in the M-L bond strength is commonly described by the Dewar Chatt Duncanson (DCD) model involving a $\sigma$-donor and $\pi$-acceptor capability of the ligand (see for instance the Scheme 1 for a phosphine ligand-metal interaction). ${ }^{1}$

${ }^{3-5}$ Combination of these two effects leads to the global electronic effect of the ligand.
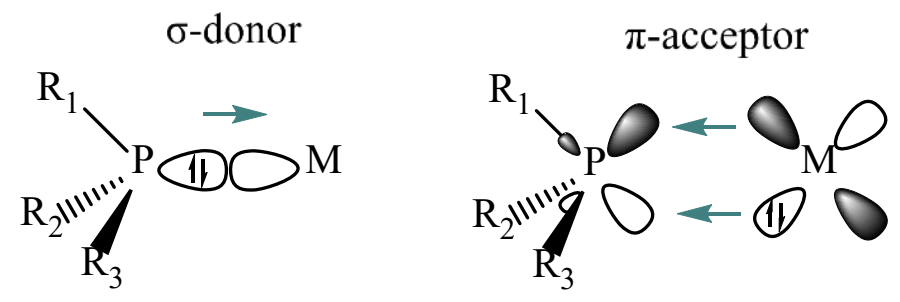

Scheme 1. Donor-acceptor interaction in transition metal complexes with phosphine as described by the DCD model.

Since several decades, many works have been devoted to the evaluation of these effects. The first and most known one refers to the seminal work of Tolman which defines the Tolman Electronic Parameter (TEP) descriptor based on the $\mathrm{A}_{1}$-symmetrical CO stretching frequency of $\left[(\mathrm{L}) \mathrm{Ni}(\mathrm{CO})_{3}\right]$ complexes. ${ }^{6}$ The TEP gives an experimental evaluation of the $\pi$-acceptor and net donor contribution of the ligands. From there, computational approaches were also developed to propose new descriptors issued from the TEP, as the calculated electronic parameter (CEP), ${ }^{7}$ the semiempirical electronic parameter (SEP) ${ }^{8}$ or a mode-decoupled local TEP (LTEP). ${ }^{9}$ These developments could show the great benefit brought by theory on this topic, but also how valuable complementary experimental and theoretical works are to describe ligands effects. Among the 
various theoretical approaches that have been developed to describe the metal-ligand bonding and successfully applied for the description of ligand electronic effects, ${ }^{10}$ one can for instance cite the energy decomposition analysis (EDA) combined to the natural orbitals for chemical valence (NOCV) analysis ${ }^{11-14}$ or the natural bond orbital (NBO) approach. ${ }^{15-17}$ Using quantum mechanics/molecular mechanics (QM/MM) calculations, Suresh and coworkers were also able to determine molecular electrostatic potential (MESP) parameters from which electronic and steric descriptors can be obtained. ${ }^{18-19}$ All these methods perform well but it is still interesting to confront them to experimental data to evaluate their performance. Experimentally, several approaches in addition to Tolman's have indeed been proposed to probe these electronic effects. Spectroscopy $\left(\mathrm{NMR},{ }^{20-21}\right.$ photoelectron spectroscopy, $\left.{ }^{22-23} ..\right)$ is one of the method of choice as it enables to directly survey the electronic and/or vibrational structure of the studied systems. For instance, Mampa et al. have demonstrated that it was possible to distinguish $\sigma$ and $\pi$ contributions for phosphine and phosphite ligands by joining IR and NMR data of iron-based complexes. ${ }^{21}$ This approach was successfully applied also for weak $\pi$-acceptor ligands such as $\mathrm{P}\left(4-\mathrm{XC}_{6} \mathrm{H}_{4}\right)_{3}$. Ligand effects have also been probed by photoelectron spectroscopy (PES) ${ }^{24}$ Lichtenberger was among the firsts to introduce this method in the field of transition metals in the $70^{\text {'s. }}{ }^{25-26}$ This technique enables to probe the electronic configuration of a system by measuring its ionization energies which are related to discrete energy levels of molecular orbitals. ${ }^{27}$ According to the DCD model, the ligand electronic effect is due to the interaction of the metal orbitals with those of the ligand. PES is thus able to provide direct and critical information on the molecular orbitals (MOs) of the complex and therefore of both the $\sigma$-donor and the $\pi$-acceptor character of the ligand. Using a molecular orbital interaction scheme, Lichtenberger was able to interpret and analyze the electronic effect influence on numerous ligands, including phosphines. ${ }^{25-26,28-33}$ Another approach, 
the quantitative analysis of ligand effects (QALE), ${ }^{34-35}$ consists in the analysis of several experimental thermochemical and spectroscopic data of the complex and the ligand to extract electronic parameters describing the stereoelectronic properties of the ligand. The QALE approach has demonstrated its ability for separating the $\sigma$ and $\pi$ contributions of the ligand, but it suffers of few limitations. For instance, the weak $\pi$-acceptor ligands are not well described with this methodology. ${ }^{36}$

From these perspectives, it could be interesting to focus on descriptors that are able to build a bridge between experimental and theoretical approaches, i.e. that benefit from the in-depth analysis provided by theory but that can also be confronted to experimental data which are essential. One such example is provided by Coll et al. who evidenced the linear correlation existing between local ionization energies and TEP, providing thus a high-performance theoretical method to evaluate TEPs. ${ }^{37}$ The study herein is based on such objective. As described above, PES has already been shown to be able to provide information on ligand electronic effects. To this end, the interpretation of the spectra was done using MOs interaction scheme which could be enriched today with the development of all the powerful quantitative theoretical methods. Our aim in this project was thus to confront PES analysis to a modern chemical bond description approach. In this perspective, we have performed a systematic study on $\mathrm{LMo}(\mathrm{CO})_{5}$ complexes with $\mathrm{L}=\mathrm{CO}$ and three series of $\mathrm{L}$ tertiary phosphine ligands, namely $\mathrm{PR}_{3}$, with $\mathrm{R}=$ alkyl substituents, $\operatorname{PPh}_{\mathrm{x}} \mathrm{Me}_{(3-\mathrm{x})}(\mathrm{x}=1-3)$ and $\operatorname{PPh}_{x} \operatorname{Pyrl}_{(3-x)}\left(x=1-3\right.$ and Pyrl being a pyrrolyl group $\left.\left(\mathrm{C}_{4} \mathrm{H}_{4} \mathrm{~N}\right)\right)($ Scheme 2$)$, using a state-of-the-art photoelectron spectroscopy setup combined with DFT and EDA/ETS-NOCV calculations. Our objective was to determine to which extent this experimental method may be correlated to theoretical data. The phosphorus(III) ligands were chosen because they belong to one of the most 
used ligand family in catalytic processes ${ }^{38-41}$ and several experimental and/or theoretical works have already been devoted to the study of their electronic influence on metals. ${ }^{37,42-47}$

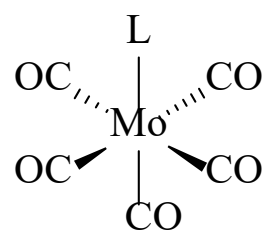<smiles>[R5][IH]I</smiles>

$\mathbf{L}=\operatorname{PPh}_{\mathbf{x}} \mathbf{M e}_{(3-\mathbf{x})}$<smiles>CP(C)c1ccccc1</smiles>

$\mathbf{L}=\mathbf{P P h}_{\mathbf{x}} \operatorname{Pyrl}_{(3-\mathrm{x})}$

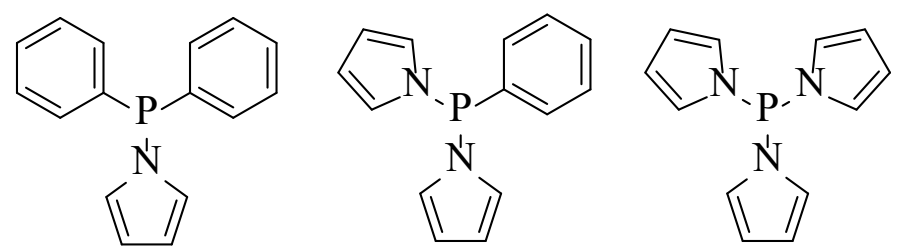

Scheme 2. Structures of the complexes studied in this work.

After a description of the experimental and theoretical approaches, experimental results will be presented for each series of ligands and compared to theoretical data. A correlation between the ionization energies of the complexes and the interaction energy obtained from EDA is found and discussed at the end of this work. 


\section{Methods}

\section{Synthetic procedure}

Molybdenum complexes were either commercially available (molybdenum hexacarbonyl, Sigma-Aldrich, St Quentin Fallavier, France) or synthetized from $\mathrm{Mo}(\mathrm{CO})_{6}$ and the corresponding tertiary phosphines upon treatment with trimethylamine oxide in acetonitrile. Characterization details of the complexes are given in the Supplementary Material.

\section{Photoelectron spectroscopy using synchrotron radiation}

Experiments were carried out on the DESIRS beamline at the SOLEIL synchrotron facility in St. Aubin (France) ${ }^{48}$ This undulator-based ${ }^{49}$ VUV-beamline is equipped with a $6.65 \mathrm{~m}$ normal incidence monochromator ${ }^{50}$ proposing several gratings depending on the required flux/resolution compromise. A $200 \mathrm{gr} / \mathrm{mm}$ grating was used, offering a photon flux in the $10^{12}-10^{13} \mathrm{ph} / \mathrm{s}$ range with a moderate energy resolution ( $12 \mathrm{meV}$ at $10 \mathrm{eV}$ photon energy). The slits were set to deliver a photon energy bandwidth between 5 and $15 \mathrm{meV}$ at $9 \mathrm{eV}$ and the second order light was removed with an upstream gas filter filled with 0.20 mbar of $\mathrm{Kr}$ or 0.15 mbar of Xe (depending on the energy range considered).$^{51}$ Absolute energy calibration was obtained by using the $4 \mathrm{~s}^{2} 4 \mathrm{p}^{6} \rightarrow$ $4 s^{2} 4 p^{5}\left({ }^{2} \mathrm{P}_{1 / 2}\right) 6 \mathrm{~s}$ absorption line of $\mathrm{Kr}^{52}$

Ca. $1 \mathrm{~g}$ of compound was deposited on a glass wool nest in a home-made oven installed in the SAPHIRS vacuum chamber. ${ }^{53}$ The temperature was adjusted for each molecule, from $25^{\circ} \mathrm{C}$ up to $160^{\circ} \mathrm{C}$. The generated vapor was transported with the help of 0.5 to 1 bar helium flow and expanded through a $70 \mu \mathrm{m}$ nozzle. After traversing a $\varnothing=1 \mathrm{~mm}$ double skimmer, the molecular beam is crossed at a right angle with the synchrotron radiation inside the interaction region of the versatile DELICIOUS III electron/ion imaging coincidence spectrometer ${ }^{54}$ Electrons and ions 
produced in the photoionization process were analyzed in coincidence by two velocity map imaging (VMI) analyzers. Photoelectrons were collected using a $176 \mathrm{~V} / \mathrm{cm}$ extraction DC field corresponding to photoelectrons kinetic energies up to $6 \mathrm{eV}$ with an energy resolution of $\Delta \mathrm{E} / \mathrm{E}=$ $5 \%$. Typically, the $6.6-11 \mathrm{eV}$ energy range was scanned with $20 \mathrm{meV}$ or $40 \mathrm{meV}$ energy steps. After a mathematical treatment of mass-selected photoelectron images, ${ }^{55}$ 2D-photoelectron matrixes are plotted as a function of the photon energy and of the electron kinetic energy. Extracting photoelectrons with kinetic energies comprised between 0 and $150 \mathrm{meV}$ gives the slow photon electron spectra (SPES). Error bars shown on the SPES have been obtained by assuming an initial Poisson distribution on the image pixels and by applying standard error propagation formulas. Appearance energies (AEs) and vertical ionization energies (IEvert) are given with an estimated error of $30 \mathrm{meV}$ (taking into account the scan steps, the precision in the kinetic energies and in the photon energy). The photon flux (photodiode AXUV100 from IRD) was recorded at each scan point for normalization purposes and hence, all spectra are corrected from false coincidences and photon flux variation but not from the oven signal variation (due to the consumption of the sample). Finally, the ionization band envelops were fitted using an asymmetric Gaussian following a similar procedure to the one developed by Lichtenberger. ${ }^{25,56}$

\section{Theoretical method}

Two types of calculations were performed in this work: DFT-based calculations to access the electronic structure of the studied complexes and energy decomposition analysis to describe the $\mathrm{L}-\mathrm{Mo}(\mathrm{CO})_{5}$ bond.

Electronic structure calculations were performed using the GAUSSIAN 09 package. ${ }^{57}$ Geometry optimizations and frequency calculations were obtained with the density functional theory (DFT)- 
based PBE0 method ${ }^{58-59}$ coupled with the triple- $\zeta$ Ahlrichs-type basis set def2-TZVP. ${ }^{60}$ Vibrational analysis served to locate minima (no imaginary frequency). A full Natural Bond Orbital (NBO, v3.1) analysis was also performed to obtain in particular the localized partial charges and NBOs on the ligand. To compute energies, we have chosen to use the long-range corrected hybrid LC$\omega$ PBE0 (also known as LC- $\omega$ PBEh) functional ${ }^{61}$ using an IP-tuned range-separation parameter $(\omega$ $=0.3$ Bohr $^{-1}$ ) combined with the def2-TZVP basis set. The IP-tuning procedure has been shown to provide very accurate estimations of IEs and is discussed in detail in the work of Gallandi et al. ${ }^{62}$ Adiabatic and vertical ionization energies were accordingly calculated with this method from the energy difference between the ion with an optimized geometry and the ground-state neutral's geometry, respectively, and the ground-state neutral complex. The energies of the highest KohnSham (KS) orbitals (HOMOs) of the neutral complexes were also computed and served for the interpretation of the photoelectron spectra pattern. Although it is known that KS orbitals eigenvalues predict $\mathrm{IE}_{\text {vert }}$ with very large absolute errors, ${ }^{63}$ Zhan et al. ${ }^{64}$ and Gengeliczki et al. ${ }^{65}$ nevertheless showed that they may be used in the same way as Hartree-Fock (HF) orbitals with Koopman's theorem by using a correction factor. In practice, the negative of the calculated KS orbitals energies have to be shifted so that the HOMO corresponds to the first vertical ionization energy on the SPES.

Finally, the interaction between the phosphine ligand and its $\mathrm{Mo}(\mathrm{CO})_{5}$ counterpart was probed by an energy decomposition analysis (EDA) following a Morokuma-like energy partition of the bond, ${ }^{66-69}$ using the Amsterdam Density Functional (ADF) program ${ }^{70}$ at the BP86D3BJ/TZ2P(ZORA) level of theory. ${ }^{71-74}$ The EDA scheme enables to partition the interaction energy $\Delta \mathrm{E}_{\text {int }}$ between the fragments into three terms: i) the repulsive Pauli interaction, $\Delta \mathrm{E}_{\text {Pauli, }}$ which includes the destabilizing interactions between occupied orbitals, ii) the classical 
electrostatic interaction, $\Delta \mathrm{E}_{\text {elstat, }}$, between the fragments and iii) the orbital interaction, $\Delta \mathrm{E}_{\text {orb }}$, which is associated to the relaxation and the mixing of the orbital between the fragments. Combining the EDA approach with the natural orbitals for chemical valence (NOCV) theory, ${ }^{12,68,75}$ enables to further decompose qualitatively and quantitatively the $\Delta \mathrm{E}_{\text {orb }}$ term into the different deformation density contributions of the bonding $\left(\Delta \mathrm{E}_{\mathrm{orb}, \sigma}, \Delta \mathrm{E}_{\mathrm{orb}, \pi . .}\right)$. NOCVs with the same absolute energy eigenvalues (and opposite sign) can be grouped together to describe charge-transfer channels between the molecular fragments. The visualization of these pairwise NOCVs allows their assignment as donating and backdonating processes.

All calculations details are given in the Supplementary Information.

\section{Results and Discussion}

Molybdenum hexacarbonyl was the first complex to be studied to serve as the reference compound. Many gas phase experimental or theoretical works have already been undertaken on this molecule and its valence photoionization process is well-described in the literature. The SPES of $\mathrm{Mo}(\mathrm{CO})_{6}{ }^{+\bullet}$ was recorded with an oven temperature at $60^{\circ} \mathrm{C}$ and is presented in Figure 1.

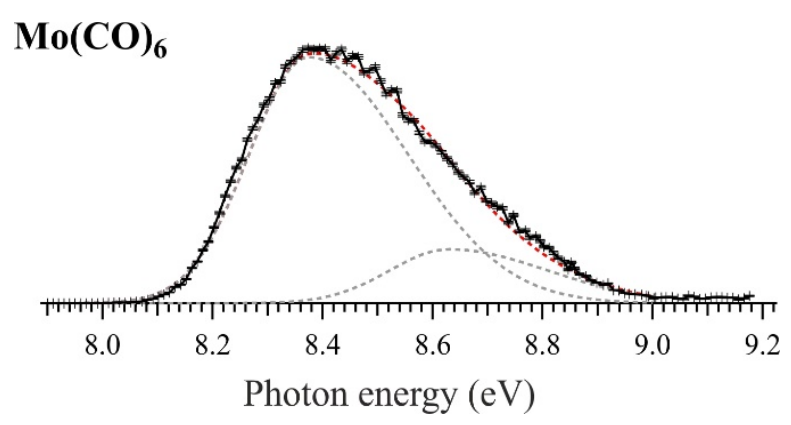

Figure 1. SPES of the $\mathrm{Mo}(\mathrm{CO})_{6}{ }^{+\bullet}$ ion recorded in the 7.9-9.2 $\mathrm{eV}$ energy range. Plain lines represent the experimental spectrum whereas dotted lines are the asymmetric Gaussian curves used to fit the data. 
A broad band is observed in the 8.0-9.0 eV region and exhibits a small shoulder on the high energy edge. In the 80 's, Hubbard and Lichtenberger showed that this shoulder could be attributed to the vibrational progression of the $v 1$ stretching mode of the ion. ${ }^{76}$ We have accordingly fitted the global band by taking into account this feature. Two asymmetric Gaussian curves have thus been necessary to describe the SPES, the first one related to the ionization of orbitals mainly with a d character (see below) and the second one to the $v 1$ progression. Both are shown with dotted lines in Fig. 1 as well as the resulting envelops (red dotted line). This gives rise to an estimation of the vertical ionization energy of the complex: $\mathrm{IE}_{\text {vert }}\left(\mathrm{Mo}(\mathrm{CO})_{6}\right)=8.37 \pm 0.03 \mathrm{eV}$. This results agrees pretty well with the work of Hubbard and Lichtenberger ${ }^{76}(8.45 \mathrm{eV})$ as well as other experimental $^{45,77}$ and theoretical ${ }^{78-79}$ ones. We also estimated the adiabatic IE of $\mathrm{Mo}(\mathrm{CO})_{6}$ to be $\mathrm{IE}_{\mathrm{ad}}\left(\mathrm{Mo}(\mathrm{CO})_{6}\right)=8.13 \pm 0.03 \mathrm{eV}$, very close from our calculated value of $8.16 \mathrm{eV}$ and in satisfying accordance with the previous work of Chen et al. who measured a value of $8.21 \pm 0.03 \mathrm{eV} \cdot{ }^{80} \mathrm{As}$ already outlined, the band observed in the spectrum in Figure 1 is attributed to the ionization on the triply degenerate $t_{2 g}$ set of orbitals of the complex having a $\left(\mathrm{Mo} 4 \mathrm{~d}+\mathrm{CO}\left(\pi^{*}\right)\right)$ character. $^{78}$ Changing one $\mathrm{CO}$ group by another ligand L decreases the symmetry of the molecule and leads to a splitting of the $t_{2 g}$ set. One obtains then the doubly degenerate e and the $b 2$ sets. This feature is visualized in our SPES and will be discussed for the different series of studied ligands.

The first series of ligands studied is the $\mathrm{PR}_{3}=$ alkyl set. SPES of $\mathrm{LMo}(\mathrm{CO})_{5}{ }^{+\bullet}$ ions with $\mathrm{L}=\mathrm{PMe}_{3}$, $\mathrm{PEt}_{3}$ and $\mathrm{P} i \mathrm{Pr}_{3}$ were obtained by heating the complexes from $50^{\circ} \mathrm{C}\left(\mathrm{PMe}_{3}\right)$ to $95^{\circ} \mathrm{C}\left(\mathrm{P} i \mathrm{Pr}_{3}\right)$ and are shown in Figure 2a)-c). In the 7.0 to $10.5 \mathrm{eV}$ energy range, different noticeable features are present on the SPES as a function of alkyl substituents. The first observation from the SPES presented here concerns the measured adiabatic ionization energies which vary from $7.32 \pm 0.03 \mathrm{eV}$ for $\mathrm{PMe}_{3}$ to $7.21 \pm 0.03$ for $\mathrm{PEt}_{3}$ and $7.16 \pm 0.03 \mathrm{eV}$ for $\mathrm{P} \mathrm{Pr}_{3}$ within $0.06 \mathrm{eV}$ agreements with calculated 
Table 1. Experimental and calculated adiabatic and vertical ionization energies of the $\mathrm{LMo}(\mathrm{CO})_{5}$ complexes (in $\mathrm{eV}$ ).

\begin{tabular}{|c|c|c|c|c|c|}
\hline \multirow[b]{2}{*}{$\mathbf{L}$} & \multicolumn{2}{|c|}{$\mathbf{I E}_{\mathbf{a d}}$} & \multicolumn{3}{|c|}{$I_{\text {vert }}$} \\
\hline & exp. ${ }^{a}$ & calc. & $\begin{array}{c}\text { exp. }^{\mathrm{a}} \\
\text { this work }\end{array}$ & $\begin{array}{c}\text { calc. } \\
\text { this work }\end{array}$ & other works \\
\hline $\mathrm{CO}$ & 8.13 & 8.16 & 8.37 & 8.45 & see text \\
\hline $\mathrm{PMe}_{3}$ & 7.32 & 7.26 & $7.55 ; 7.74 ; 9.84$ & 7.53 & $7.64{\text { (calc. })^{81}}^{81}$ \\
\hline $\mathrm{PEt}_{3}$ & 7.21 & 7.17 & $7.45 ; 7.67 ; 9.52$ & 7.46 & \\
\hline $\mathrm{PiPr}_{3}$ & 7.16 & 7.11 & $7.43 ; 7.67 ; 9.31$ & 7.37 & \\
\hline $\mathrm{PPh}_{3}$ & 6.99 & 7.03 & $7.37 ; 7.57 ; \sim 8.7$ & 7.30 & $7.30{\text { (calc. })^{81}}^{11}$ \\
\hline $\mathrm{PPh}_{2} \mathrm{Me}$ & 7.14 & 7.13 & $7.44 ; 7.62 ; \sim 9.1$ & 7.38 & \\
\hline $\mathrm{PPhMe}_{2}$ & 7.16 & 7.20 & 7.48; 7.67; 9.2 & 7.44 & \\
\hline $\mathrm{PPh}_{2} \mathrm{Pyrl}$ & 7.25 & 7.33 & $\sim 7.5 ; \sim 7.7$ & 7.51 & \\
\hline $\mathrm{PPhPyrl}_{2}$ & 7.42 & 7.50 & not measured & 7.69 & \\
\hline $\mathrm{PPyrl}_{3}$ & 7.59 & 7.67 & not measured & 7.95 & \\
\hline
\end{tabular}

${ }^{\mathrm{a}}$ obtained with an estimated error of $0.03 \mathrm{eV}$

values (Table 1). These energies can be linked to the global interaction of the ligand, which includes orbital, steric, electrostatic effects. One can indeed expect that a stronger interacting ligand will tend to stabilize the metal within the complex and then increase its ionization energy. For instance, the interaction of occupied $t_{2 g}$ orbitals of the metal with low-lying empty $\pi^{*}$ MOs of the ligand results in a bonding $\mathrm{t}_{2 \mathrm{~g}} \mathrm{MO}\left(\mathrm{d}\right.$ (metal) $+\pi^{*}$ (ligand)), lower in energy than the initial $\mathrm{t}_{2 \mathrm{~g}}$ orbital. In case the ejected electron is in the direct environment of the metal (i.e. the HOMO has a $\mathrm{d}$ (metal) character), it results thus in higher IEs. As the CO ligand shows a strong $\pi$-acceptor effect, it explains the high $\mathrm{IE}_{\mathrm{ad}}$ of the $\mathrm{Mo}(\mathrm{CO})_{6}$ complex $\left(8.13 \mathrm{eV}\right.$, Table 1). For the $\mathrm{PR}_{3}$ set, the $\mathrm{IE}_{\mathrm{ad}}$ trend indicates that the $\mathrm{PMe}_{3}$ group is interacting more strongly with Mo compared to larger alkyls and has thus a greater net donor capability. This result may seem somewhat surprising as 
Table 2. Hybridization of the $P$ lone-pair and partial charges $(q)$ of the ligand $\mathrm{PX}_{3}$ in the neutral and charged $\mathrm{LMo}(\mathrm{CO})_{5}$ complex obtained from by the NBO analysis performed at the PBE0/Def2TZVP level of theory.

\begin{tabular}{|c|c|c|c|c|}
\hline \multirow[b]{2}{*}{$\mathbf{L}$} & \multicolumn{2}{|c|}{ P lone-pair hybridization } & \multicolumn{2}{|c|}{ L partial charge } \\
\hline & $\% s(P) l p$ & $\% \mathrm{p}(\mathrm{P}) \mathrm{lp}$ & $\mathrm{LMo}(\mathrm{CO})_{5}$ & $\mathrm{LMo}(\mathrm{CO}) 5^{+\bullet}$ \\
\hline$\overline{\mathrm{PMe}_{3}}$ & 50.14 & 49.85 & 0.649 & 0.770 \\
\hline PEt $_{3}$ & 50.78 & 49.21 & 0.645 & 0.804 \\
\hline $\mathbf{P i P r}_{3}$ & 44.57 & 55.42 & 0.620 & 0.806 \\
\hline $\mathbf{P P h}_{3}$ & 45.31 & 54.67 & 0.577 & 0.889 \\
\hline $\mathbf{P P h}_{2} \mathrm{Me}$ & 47.16 & 52.83 & 0.605 & 0.886 \\
\hline $\mathrm{PPhMe}_{2}$ & 48.53 & 51.46 & 0.628 & 0.856 \\
\hline $\mathbf{P P h}_{2} \mathbf{P y r}$ & 48.16 & 51.83 & 0.575 & 0.950 \\
\hline PPhPyr2 & 50.38 & 49.61 & 0.575 & 0.967 \\
\hline PPyr3 & 54.52 & 45.48 & 0.571 & 1.478 \\
\hline
\end{tabular}

larger alkyl groups are expected to have a larger donor ability due to inductive effects. This trend was however confirmed by the decrease of the Mo-P bond length from $\mathrm{PMe}_{3}$ to $\mathrm{P} \mathrm{Pr}_{3}$ (resp. from 2.51 to $2.61 \AA$ ) and the NBO analysis of the partial charges: the carried charge by the $\mathrm{PR}_{3}$ ligands decreases from 0.649 for $\mathrm{PMe}_{3}$ down to 0.620 for $\mathrm{P}_{i} \mathrm{Pr}_{3}$, showing a reduced electron deficiency on the ligand (Table 2) and thus, a smaller donating effect for larger alkyls. Further, two recent experimental works also reached the same conclusions. First, Kendall et al. studied the steric and electronic influences of Buchwald-type alkyl-JohnPhos ligands in $\operatorname{LCr}(\mathrm{CO})_{5}$ complexes and showed using IR data that the net-donating ability of the phosphines was decreasing with the increasing size. ${ }^{82}$ They explained this finding by the influence that steric effects also have on the 
L-M interaction and which thus favor smaller alkyl groups. Then, in a previous study, we carried out an investigation on $\mathrm{L}-\mathrm{Au}^{+}-\mathrm{CO}$ complexes using mass spectrometry techniques to measure the $\mathrm{LAu}^{+}-\mathrm{CO}$ bond-dissociation energies. The same observations on the alkyl size effect arise and were discussed by means of electrostatic interaction and Pauli repulsion as determined by EDA. ${ }^{83}$ In the present work, the global donor effect of $\mathrm{PR}_{3}$ ligands on $\mathrm{LMo}(\mathrm{CO})_{5}$ complexes is discussed further in the light of the EDA results, but first, the experimental results are analyzed in more details.

On the SPES in Fig. 2a)-c), a broad band, similar to that of $\mathrm{Mo}(\mathrm{CO})_{6}$, is observed in the ca. $7.5 \mathrm{eV}$ region. This band exhibits two local maxima which are attributed to ionization of the e and the b2 sets. The small shoulder corresponding to the $v 1$ progression (see above) is also observed. Attribution of these bands can be done following Koopman's theorem. The energy position of the HOMO of the different complexes are displayed in Figure 2a)-c) (red sticks). The agreement between the bands position and the KS-orbital's energies is noteworthy and points out the efficiency of the IP-tuned LC- $\omega$ PBEh method. The first band observed can be linked to ionization from the HOMO, HOMO-1 and HOMO-2orbitals. The shapes of these three KS-orbitals are displayed in Figure 3 and indicate that the two orbitals of the e set (HOMO and HOMO-1) both backbond to three $\mathrm{CO}$ and one phosphine whereas the $\mathrm{b} 2$ orbital backbonds to four $\mathrm{CO}$. The difference in energy between these two sets of orbitals (e and b2) can thus be linked to the backbonding variation between a $\mathrm{CO}$ and a phosphine bound to Mo and gives an evaluation of the $\pi$-acceptor effect of the ligand. The experimental difference between the two maxima in the first bands is respectively $0.19,0.22$ and $0.24 \mathrm{eV}$ from methyl to iso-propyl showing that the $\pi$ stabilization is decreasing by increasing the alkyl size (Table 1 ). Note that the $\mathrm{PR}_{3} \pi$-acceptor 


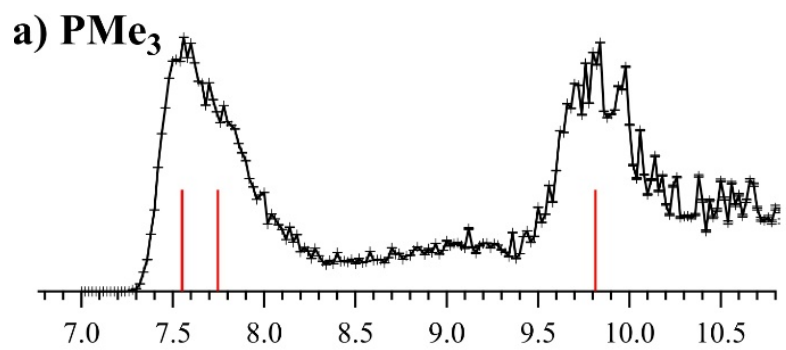

b) $\mathbf{P E t}_{3}$

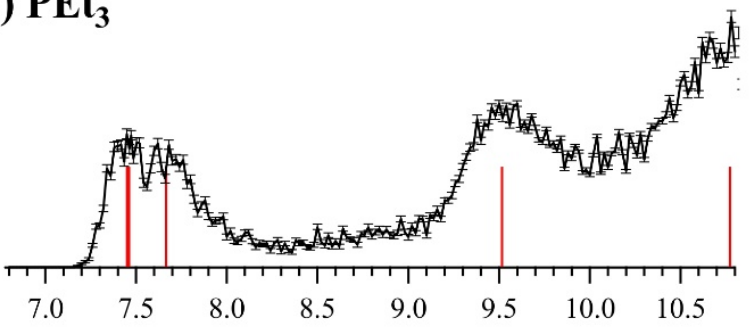

c) $\operatorname{PiPr}_{3}$

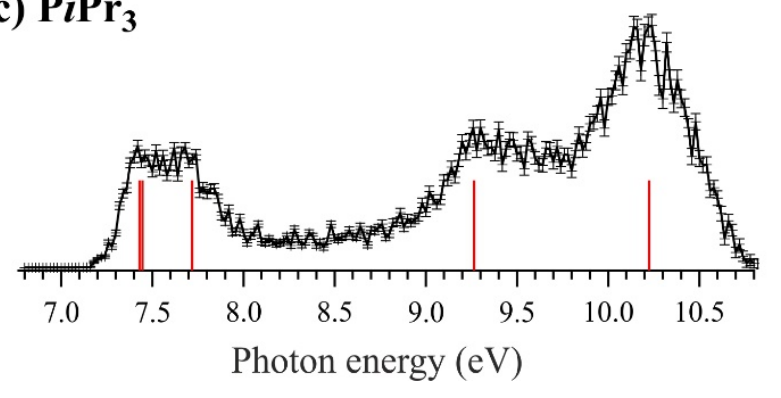

d) $\mathbf{P P h}_{3}$

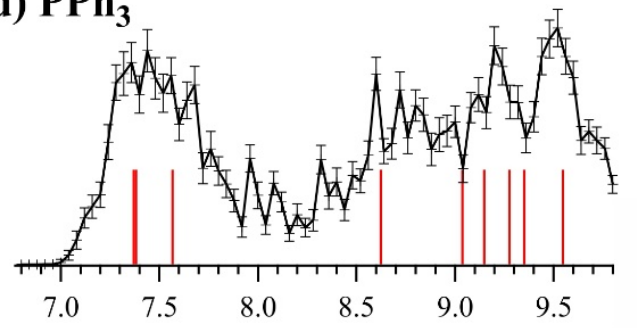

e) $\mathbf{P P h}_{2} \mathbf{M e}$

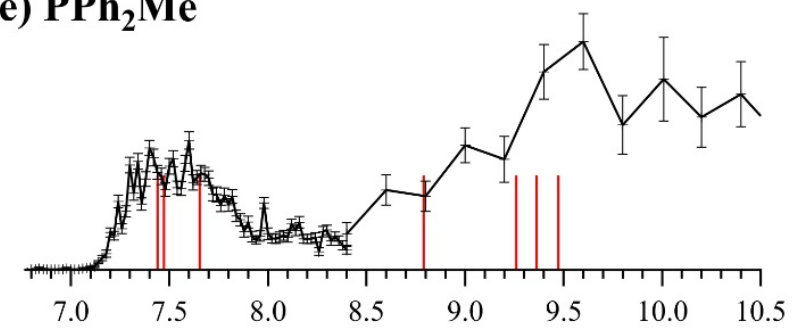

f) $\mathrm{PPhMe}_{2}$

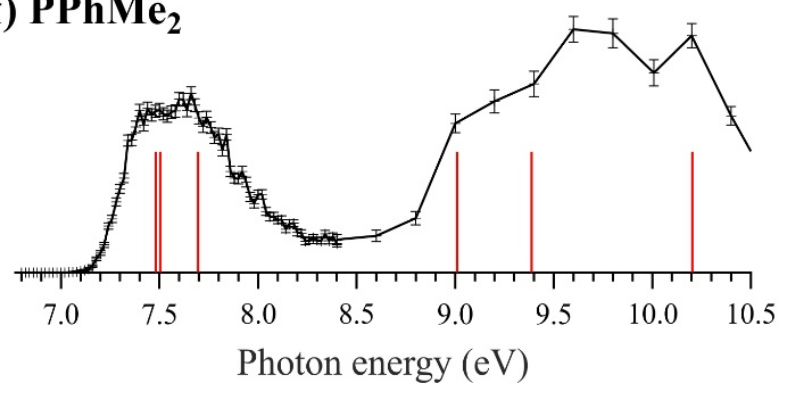

Figure 2. $\mathrm{SPES}$ of the $\mathrm{LMo}(\mathrm{CO})_{5}{ }^{+}$ions for the a)-c) $\mathrm{L}=\mathrm{PR}_{3}$ (with $\mathrm{R}=$ alkyl) and d)-f) $\mathrm{L}=\mathrm{PPh}_{\mathrm{x}} \mathrm{Me}_{(3-}$ x) series recorded in the 6.8-10.5 eV energy range. Red sticks represent the calculated energies of the first HOMOs of the neutral complexes. Because of a lack of experiment time, the spectra e) and f) were recorded in two steps: a first one from 6.6 to $8.4 \mathrm{eV}$ with $20 \mathrm{meV}$ steps and a second one from 8.4 to $10.5 \mathrm{eV}$ with $200 \mathrm{meV}$ steps.

orbital formally corresponds to a $\left(\sigma^{*}(\mathrm{P}-\mathrm{R})+3 \mathrm{~d}(\mathrm{P})\right)$ hybridized orbital (Scheme 1$) \cdot{ }^{84}$ This experimental finding is supported by calculations which give also an increase of $\mathrm{HOMO} / \mathrm{HOMO}-$ 1 and HOMO-2 KS-orbitals energy difference by changing the alkyl size (resp. 0.20, 0.21 and 0.27 $\mathrm{eV}$ for $\mathrm{Me}$ to $i \mathrm{Pr}$, see $\mathrm{SI})$. This $\pi$-acceptor effect remains however much smaller than for a COgroup (as seen by the e set having a lower energy than the b2 set). 


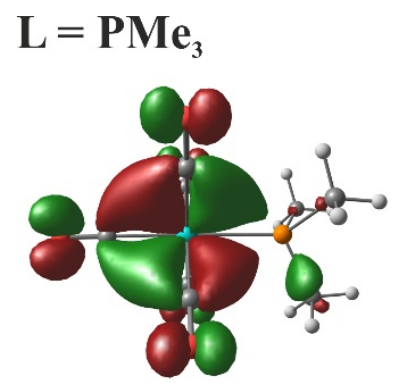

$\mathrm{HOMO}(\mathrm{e})$

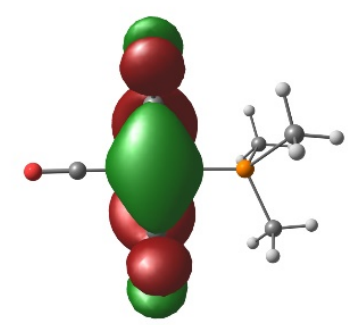

HOMO-2 (b2)

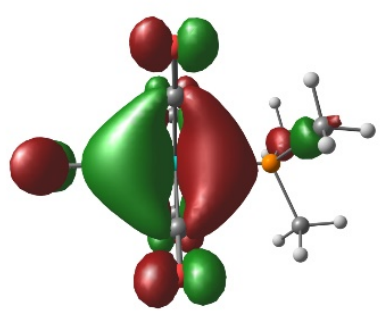

HOMO-1 (e)

Figure 3. Kohn-Sham orbitals of $\mathrm{Me}_{3} \mathrm{PMo}(\mathrm{CO})_{5}$ obtained at the LC- $\omega \mathrm{PBEh} / \mathrm{Def} 2-\mathrm{TZVP}$ level of theory. The symmetry is indicated into brackets. Isosurface value: 0.03 a.u.

Furthermore, another broad band is present on the SPES in Fig. 2a)-c), at around $9.5 \mathrm{eV}$. It is attributed to ionization of the coordinated phosphine lone pair orbital which is involved in the $\sigma$ bond with Mo. Yarbrough and Hall indeed compared the photoelectron spectra of several $\mathrm{LMo}(\mathrm{CO})_{5}$ phosphine complexes with those of uncoordinated L ligands. ${ }^{85}$ They could show that, under coordination, this P lone-pair band is the most destabilized because of its direct Mo-P interaction. Hence, the position of this band in the SPES is able to reflect the strength of the $\sigma$ donation of the phosphine ligand: the more destabilized it appears, the stronger is the $\sigma$-donation. In Fig. 2a)-c), the position of this band is shifted to lower energies by increasing the alkyl size: from $9.84 \mathrm{eV}$ for $\mathrm{PMe}_{3}$ to $9.52 \mathrm{eV}$ for $\mathrm{PEt}_{3}$ and $9.31 \mathrm{eV}$ for $\mathrm{P}_{2} \mathrm{Pr}_{3}$. Note that the $\mathrm{PMe}_{3}$ band position measured at $9.84 \mathrm{eV}$ is in great accordance with the $\mathrm{He}(\mathrm{I})$ spectrum of the same Mo complex of Lichtenberger and Jatchko who measured a band at $9.87 \mathrm{eV} .{ }^{30,86}$ These energies have to be compared with those of the P-lone pair in the uncoordinated ligand. Experimental data on the $\mathrm{P}$ 
lone-pair band position could only be found for $\mathrm{PMe}_{3}$ and $\mathrm{PEt}_{3}$ in two works giving either 8.79 and $8.52 \mathrm{eV}^{85}$ or 8.60 and $8.27 \mathrm{eV}^{87}$ for $\mathrm{PMe}_{3}$ and $\mathrm{PEt}_{3}$, respectively. In both cases, the energy difference between these bands and the experimental bands observed in this work shows about the same difference (ca 1.0 or $1.2 \mathrm{eV}$ ). We have also evaluated the energy difference of these bands with theory as no experimental data were available for $\mathrm{P} i \mathrm{Pr}_{3}$. The results are given in the SI and indicate also the same energy difference between $\mathrm{PMe}_{3}$ and $\mathrm{PEt}_{3}$, but a larger one for $\mathrm{P}_{i \mathrm{Pr}_{3}}$

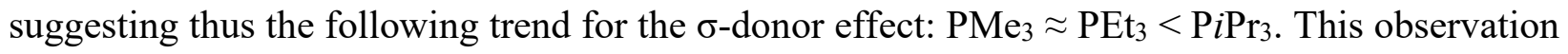
is consistent with the known inductive effects of the alkyl groups: an increased $\sigma$-donation is indeed expected by increasing the alkyl size.

Table 3. EDA results of the L-Mo bond in $\mathrm{LMo}(\mathrm{CO})_{5}$ complexes (in $\mathrm{kcal} / \mathrm{mol}$ ).

\begin{tabular}{lcccc}
\hline $\mathbf{L}$ & $\Delta \mathbf{E P a u l i}$ & $\Delta \mathbf{E}_{\text {elstat }}{ }^{\mathrm{a}}$ & $\Delta \mathbf{E}_{\text {orb }}{ }^{\mathrm{a}}$ & $\Delta \mathbf{E}_{\text {int }}$ \\
\hline PMe$_{3}$ & 96.28 & -88.72 & -48.26 & -40.70 \\
& & $(64.8 \%)$ & $(35.2 \%)$ & \\
PEt $_{3}$ & 92.46 & -84.44 & -47.26 & -39.25 \\
& & $(64.1 \%)$ & $(35.9 \%)$ & \\
PiPr $_{3}$ & 87.96 & -80.71 & -45.63 & -38.38 \\
& & $(63.9 \%)$ & $(36.1 \%)$ & \\
PPh $_{3}$ & 81.97 & -69.62 & -45.55 & -33.20 \\
& & $(60.4 \%)$ & $(39.6 \%)$ & \\
PPh $_{2} \mathbf{M e}$ & 87.78 & -76.58 & -47.19 & -35.99 \\
& & $(61.9 \%)$ & $(38.1 \%)$ & \\
PPhMe $_{2}$ & 91.57 & -81.87 & -48.08 & -38.39 \\
& & $(63.0 \%)$ & $(37.0 \%)$ & \\
PPyrlPh $_{2}$ & 84.92 & -69.99 & -47.31 & -32.38 \\
& & $(59.7 \%)$ & $(40.3 \%)$ & \\
PPyrl $_{2} \mathbf{P h}$ & 88.20 & -70.68 & -49.18 & -31.66 \\
& & $(59.0 \%)$ & $(41.0 \%)$ & \\
PPyrl $_{3}$ & 90.16 & -70.31 & -51.23 & -31.38 \\
& & $(57.8 \%)$ & $(42.2 \%)$ & \\
\hline
\end{tabular}

a The values in parentheses give the contribution of $\Delta \mathrm{E}_{\text {elstat. }}$ and $\Delta \mathrm{E}_{\text {orb. }}$ to the total attractive interactions $\left(\Delta \mathrm{E}_{\text {elstat }}+\Delta \mathrm{E}_{\text {orb }}\right)$. 
The results of the energy decomposition analysis performed on the $\mathrm{L}-\mathrm{Mo}(\mathrm{CO})_{5}$ bond for the $\mathrm{L}=$ $\mathrm{PR}_{3}(\mathrm{R}=$ alkyl $)$ are summarized in Table 3 . The $\Delta \mathrm{E}_{\text {int }}$ term appears to be the largest for $\mathrm{PMe}_{3}(-$ $40.70 \mathrm{kcal} / \mathrm{mol})$ and decreases slightly for $\operatorname{PEt}_{3}(-39.25 \mathrm{kcal} / \mathrm{mol})$ and $\operatorname{Pi} \operatorname{Pr}_{3}(-38.38 \mathrm{kcal} / \mathrm{mol})$. This result can be correlated with the decrease of $\mathrm{IE}_{\text {ad }}$ observed from $\mathrm{PMe}_{3}$ to $\mathrm{P}_{i \mathrm{Pr}}$ (Table 1) that was rationalized by suggesting a stronger interaction between $\mathrm{PMe}_{3}$ and the metal (see above). Decomposition of this term indicates that the total attractive interaction between the $\mathrm{PR}_{3}$ and the $\mathrm{Mo}(\mathrm{CO})_{5}$ fragments is dominated by the electrostatic interaction term $\Delta \mathrm{E}_{\text {elstat }}(\mathrm{about} 64 \%$ ) whereas the covalent term introduced by $\Delta \mathrm{E}_{\text {orb }}$ accounts only for $36 \%$. Frenking rationalized this important electrostatic contribution by the large $\mathrm{p}$ character of the $\sigma \mathrm{HOMO}$ of $\mathrm{PMe}_{3}$ which induces a good overlap between the phosphorous lone-pair electrons and the nucleus of the metal. ${ }^{88-89}$ The same amount of $\mathrm{p}$ character is found for $\mathrm{PEt}_{3}$ and $\mathrm{P}_{i} \mathrm{Pr}_{3}$ (above 50\%, Table 2). Furthermore, the decomposition of $\Delta \mathrm{E}_{\text {orb }}$ following the ETS-NOCV approach helps correlating the experimental results to the EDA. In Table 4, the ETS-NOCV results indicate that the deformation densities contributing to the orbital interaction on the $\mathrm{L}-\mathrm{M}(\mathrm{CO})_{5}$ bond have principally a $\sigma$-donor and a $\pi$ acceptor character $\left(\Delta \mathrm{E}_{\mathrm{orb}, \sigma}, \Delta \mathrm{E}_{\mathrm{orb}, \pi 1}\right.$ and $\left.\Delta \mathrm{E}_{\mathrm{orb}, \pi 2}\right)$. The corresponding deformation densities $\Delta \rho_{\sigma / \pi}$ are presented in Figure 3 for $\mathrm{L}=\mathrm{PMe}_{3}$ (see the SI for the others ligands). $\Delta \rho_{\sigma}$ shows clearly the $\mathrm{L} \rightarrow \mathrm{M}$ $\sigma$-donation whereas $\Delta \rho_{\pi 1}$ and $\Delta \rho_{\pi 2}$ represent the two components of the $\mathrm{L} \leftarrow \mathrm{M} \pi$ backdonation. Comparison of the $\sigma$-donor and $\pi$-acceptor contributions of the $\mathrm{L}=\mathrm{PR}_{3}$ series confirms the experimental findings: the $\sigma$-donor contribution is larger for $\mathrm{P} \mathrm{Pr}_{3}$ than for $\mathrm{PEt}_{3}$ and $\mathrm{PMe}_{3}(76.4 \%$ of the total $(\sigma+\pi)$ orbital contribution vs 74.1 and $73.6 \%$, respectively, Table 4$)$ whereas the $\pi$-acceptor character of the ligand is the highest for $\mathrm{PMe}_{3}$. It represents indeed $26.3 \%$ of the $(\sigma+\pi)$ orbital contribution vs $25.9 \%$ for $\mathrm{PEt}_{3}$ and $23.6 \%$ for $\mathrm{P} \mathrm{Pr}_{3}$ with NOCV eigenvalues for the total $\pi$ contribution decreasing from 0.50 down to 0.43 along the series (Fig. 4 and S2). The 
Table 4. ETS-NOCV of the $\mathrm{L}-\mathrm{Mo}(\mathrm{CO})_{5}$ complexes (in $\left.\mathrm{kcal} / \mathrm{mol}\right)$.

\begin{tabular}{|c|c|c|c|}
\hline $\mathbf{L}$ & $\Delta \mathbf{E}_{\text {orb }, \sigma^{b}}$ & $\Delta \mathbf{E}_{o r b, \pi 1}{ }^{\mathrm{b}}$ & $\Delta \mathbf{E}_{o r b, \pi 2^{b}}$ \\
\hline $\mathrm{PMe}_{3}$ & $\begin{array}{c}-32.8 \\
(73.6 \%)\end{array}$ & $\begin{array}{c}-5.9 \\
(13.3 \%)\end{array}$ & $\begin{array}{c}-5.9 \\
(13.2 \%)\end{array}$ \\
\hline PEt $_{3}$ & $\begin{array}{c}-31.3 \\
(74.1 \%)\end{array}$ & $\begin{array}{c}-5.5 \\
(13.1 \%)\end{array}$ & $\begin{array}{c}-5.4 \\
(12.9 \%)\end{array}$ \\
\hline PiPr3 & $\begin{array}{c}-30.1 \\
(76.4 \%)\end{array}$ & $\begin{array}{c}-4.7 \\
(11.9 \%)\end{array}$ & $\begin{array}{c}-4.6 \\
(10.1 \%)\end{array}$ \\
\hline $\mathbf{P P h}_{3}$ & $\begin{array}{c}-28.6 \\
(71.2 \%)\end{array}$ & $\begin{array}{c}-6.0 \\
(14.9 \%)\end{array}$ & $\begin{array}{c}-5.6 \\
(13.9 \%)\end{array}$ \\
\hline $\mathrm{PPh}_{2} \mathrm{Me}$ & $\begin{array}{c}-30.4 \\
(71.6 \%)\end{array}$ & $\begin{array}{c}-6.3 \\
(14.9 \%)\end{array}$ & $\begin{array}{c}-5.7 \\
(13.4 \%)\end{array}$ \\
\hline PPhMe2 & $\begin{array}{c}-31.9 \\
(72.7 \%)\end{array}$ & $\begin{array}{c}-6.2 \\
(14.1 \%)\end{array}$ & $\begin{array}{c}-5.8 \\
(13.3 \%)\end{array}$ \\
\hline PPyrlPh$_{2}$ & $\begin{array}{c}-28.3 \\
(67.0 \%)\end{array}$ & $\begin{array}{c}-7.7 \\
(18.1 \%)\end{array}$ & $\begin{array}{c}-6.3 \\
(14.9 \%)\end{array}$ \\
\hline $\operatorname{PPyrl}_{2} \mathbf{P h}$ & $\begin{array}{c}-27.7 \\
(63.0 \%)\end{array}$ & $\begin{array}{c}-8.7 \\
(19.8 \%)\end{array}$ & $\begin{array}{c}-7.6 \\
(17.2 \%)\end{array}$ \\
\hline $\mathrm{PPyrl}_{3}$ & $\begin{array}{c}-27.2 \\
(59.0 \%)\end{array}$ & $\begin{array}{c}-9.5 \\
(20.6 \%)\end{array}$ & $\begin{array}{c}-9.4 \\
(20.4 \%)\end{array}$ \\
\hline
\end{tabular}

\footnotetext{
${ }^{\text {a }}$ Only the major components are given here. A last contribution corresponding to a $\sigma$ backdonation is also present but accounts for less than $2 \%$ of the total orbital interaction $\Delta \mathrm{E}_{\text {orb. }}$ This contribution was observed and discussed by Ardizzoia et al. ${ }^{13}$

${ }^{\mathrm{b}}$ The contribution of each deformation density to the $\left(\Delta \mathrm{E}_{\mathrm{orb}, \sigma}+\Delta \mathrm{E}_{\mathrm{orb}, \pi 1 / \pi 2}\right)$ orbital interactions is indicated in parentheses.
}

Tolman analysis of these alkylphosphine ligands confirm these results: the C-O bond stretching frequency slightly varies in $\mathrm{Ni}(\mathrm{CO})_{3} \mathrm{~L}$ complexes from $2064 \mathrm{~cm}^{-1}$ for $\mathrm{PMe}_{3}$ to $2062 \mathrm{~cm}^{-1} \mathrm{for} \mathrm{PEt}_{3}$ and $2059 \mathrm{~cm}^{-1}$ for $\mathrm{P}_{i} \mathrm{Pr}_{3}$ thus revealing $\mathrm{PMe}_{3}$ more $\pi$-acceptor than $\mathrm{P}_{i \mathrm{Pr}}$ and globally more donating. ${ }^{90}$ Despite a smaller $\sigma$-donor and a larger $\pi$-acceptor effects of $\mathrm{PMe}_{3}$ compared to the other $\mathrm{PR}_{3}$ ligands, $\mathrm{PMe}_{3}$ appears as the largest global donor ligand considering the trend in $\mathrm{IE}_{\mathrm{ad}}$, the NBO partial charges on $\mathrm{PR}_{3}$ and the $\Delta \mathrm{E}_{\text {int }}$ analysis. As already outlined above, this feature is confirmed by other experimental works. ${ }^{82-83}$ The overall donating character of the ligand has 
indeed to be rationalize by considering all the energetic terms that account for the bonding. In the case of $\mathrm{PMe}_{3}$, the attractive interaction largely overtakes that of $\mathrm{PEt}_{3}$ and $\mathrm{P} i \mathrm{Pr}_{3}(137.0 \mathrm{kcal} / \mathrm{mol} \mathrm{vs}$ 131.7 and $126.3 \mathrm{kcal} / \mathrm{mol}$, respectively, Table 3) and explains this non-intuitive effect.

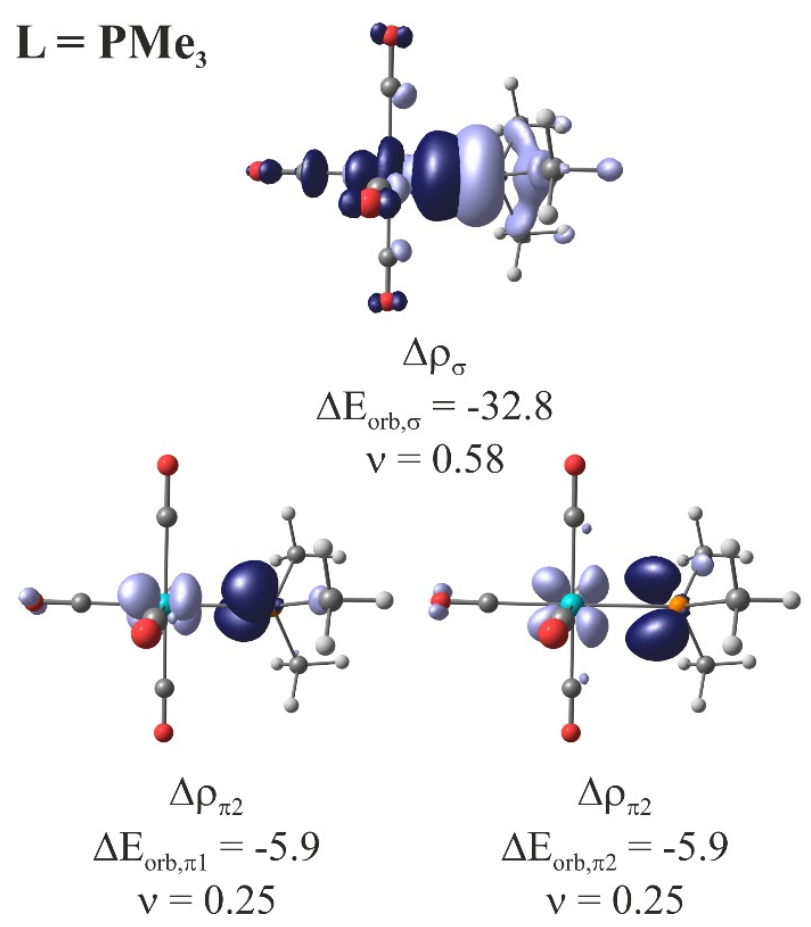

Figure 4. Contours of deformation density $\Delta \rho_{\sigma / \pi}$ connected with the pairs of interacting orbitals in the $\mathrm{Me}_{3} \mathrm{P}-\mathrm{Mo}(\mathrm{CO})_{5}$ complex. Light purple surfaces represent a loss of electron density and dark blue surfaces, a gain of electron density. The associated orbital interaction energies $\Delta \mathrm{E}_{\text {orb }}$ are given in $\mathrm{kcal} / \mathrm{mol} . v$ is the eigenvalue indicating the size of the charge flow. Isosurface value: 0.0025 a.u.

The $\mathrm{L}=\mathrm{PPh}_{\mathrm{x}} \mathrm{Me}_{(3-\mathrm{x})}$ set of ligands was studied in the same way as the $\mathrm{L}=\mathrm{PR}_{3}$ sets and resulting SPES are shown in Fig. 2a), d)-f). Complexes with phenyl group were the most difficult to vaporize and required temperatures up to $160^{\circ} \mathrm{C}\left(\mathrm{L}=\mathrm{PPh}_{3}\right)$ whereas an oven temperature of $130^{\circ} \mathrm{C}$ was sufficient to observe the $\mathrm{L}=\mathrm{PPh}_{2} \mathrm{Me}$ and $\mathrm{L}=\mathrm{PPhMe}_{2}$ complexes. Concerning the adiabatic IE, a clear energy decrease is observed by changing the number of phenyls from $0\left(\mathrm{PMe}_{3}\right.$, $\left.\mathrm{IE}_{\mathrm{ad}}=7.32 \pm 0.03 \mathrm{eV}\right)$ to $3\left(\mathrm{PPh}_{3}, \mathrm{IE}_{\mathrm{ad}}=6.99 \pm 0.03 \mathrm{eV}\right.$, see Table 1). The global interaction 
between the $\mathrm{PPh}_{\mathrm{x}} \mathrm{Me}_{(3-\mathrm{x})}$ ligands and Mo seems thus to be stronger by increasing the number of methyls. This finding is confirmed by the NBO partial charges analysis on the $\mathrm{PPh}_{\mathrm{x}} \mathrm{Me}_{(3-\mathrm{x})}$ moiety: a net decrease of the charge is observed when increasing the number of phenyls $\left(\mathrm{q}\left(\mathrm{PPh}_{\mathrm{x}} \mathrm{Me}_{(3-\mathrm{x})}\right)=\right.$

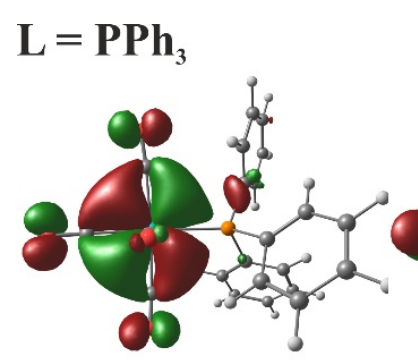

HOMO

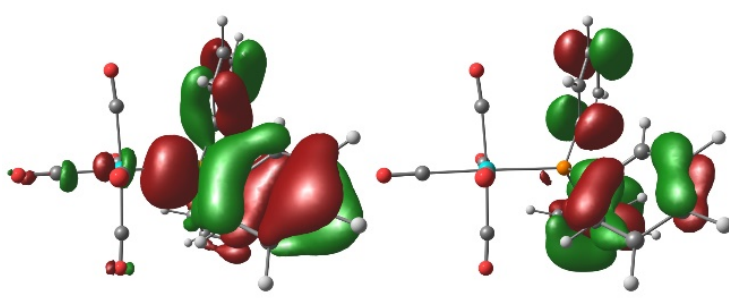

HOMO-3

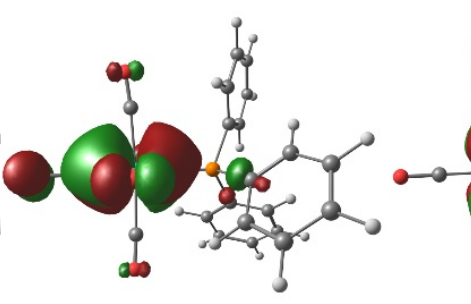

HOMO-1

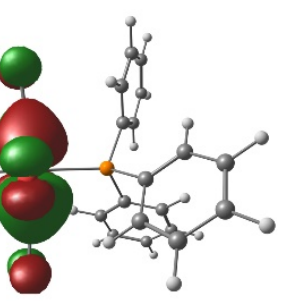

HOMO-2

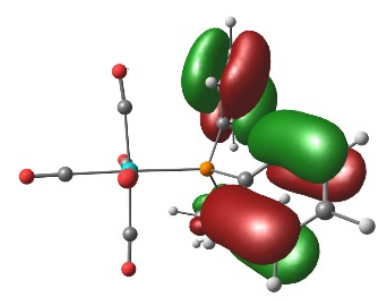

HOMO-5

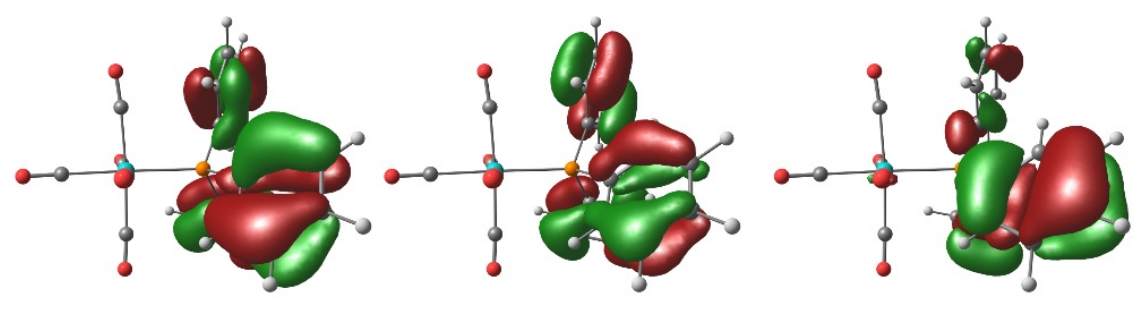

HOMO-6

HOMO-8

Figure 5. Kohn-Sham orbitals of $\mathrm{Ph}_{3} \mathrm{PMo}(\mathrm{CO})_{5}$ obtained at the LC- $\omega \mathrm{PBEh} / \mathrm{Def} 2-\mathrm{TZVP}$ level of theory. Isosurface value: 0.03 a.u.

$0.649,0.628,0.605,0.577$ for $\mathrm{x}=0$ to 3 , respectively (see Table 2$)$ ), indicating a decreased electron deficiency on $-\mathrm{PPh}_{x} \mathrm{Me}_{(3-\mathrm{x})}$ and thus an increased global donor effect following $\mathrm{PMe}_{3}>\mathrm{PPhMe}_{2}>$ $\mathrm{PPh}_{2} \mathrm{Me}>\mathrm{PPh}_{3}$. This trend is confirmed by the behavior of $\mathrm{PPhMe}_{2}, \mathrm{PPh}_{2} \mathrm{Me}$ and $\mathrm{PPh}_{3}$ observed in oxidative addition reactions of $\mathrm{Pd}(\mathrm{OAc})_{2}\left(\mathrm{PR}_{3}\right)_{2}$ complexes toward phenyl iodide: $\mathrm{PPhMe}_{2}$ is 
found to be more active than $\mathrm{PPh}_{2} \mathrm{Me}$ and $\mathrm{PPh}_{3}$ because of its higher donating ability to the metal. ${ }^{46}$, 91

Further, as for $\mathrm{L}=\mathrm{PR}_{3}$, a common structure is observed for the $\mathrm{L}=\mathrm{PPh}_{\mathrm{x}} \mathrm{Me}_{(3-\mathrm{x})} \mathrm{SPES}$ : a first intense band followed by a second one but which is much broader than for $\mathrm{PR}_{3}$. MO analysis shows that this broadening is due to the contribution of the phenyl orbitals to the HOMOs which account in this energy region (see Figure 5 in the case of $\mathrm{Ph}_{3} \mathrm{PMo}(\mathrm{CO})_{5}$ and $\mathrm{SI}$ for the others). Interpretation of the first band in terms of $\pi$-acceptor effect remains nevertheless similar to that of the $\mathrm{PR}_{3}$ set. The three first HOMOs of this series of complexes indeed possess a full d character (Fig. 5). The measured energy difference between the two first ionization energies reveal no noticeable change, respectively $0.19,0.19,0.18$ and $0.20 \mathrm{eV}$ for $\mathrm{PPh}_{\mathrm{x}} \mathrm{Me}_{(3-\mathrm{x})}$ by varying $\mathrm{x}$ from 0 to 3 (Table 1). Similarly, the calculated HOMO/HOMO-1 and HOMO-2 energies show a difference of 0.20, 0.19, 0.18 and $0.19 \mathrm{eV}$ respectively. The $\pi$-backdonation appears thus to be similar for this whole set of ligands. This observation is rather in agreement with the NBO analysis performed by Leyssens and coworkers showing that $\mathrm{PMe}_{3}$ was a slightly better $\pi$-acceptor than $\mathrm{PPh}_{3}{ }^{16}$ Concerning the higher-energy bands on the SPES on Fig. 2a),d)-f), their first contribution is also attributed to the P coordinated pair to Mo (e.g. HOMO-3 for $\mathrm{PPh}_{3}$, see Fig. 5) and the others (up to 5 in the case of $\mathrm{PPh}_{3}$ ) to the $\pi$ orbitals of the phenyls. Due to the broadness of the band, a precise evaluation of the $\sigma$ ionization energy is difficult to provide but one can still see some trend for the band position: the more phenyl groups are in the ligand, the lower in energy the band is: from $9.84 \mathrm{eV}$ for $\mathrm{PMe}_{3}$ to ca. $8.7 \mathrm{eV}$ for $\mathrm{PPh}_{3}$. These values have to be compared with the energies of the phosphorus lonepair in uncoordinated ligand. Ikuta et al. have provided the following estimation of the IEs for the set of $\mathrm{PPh}_{\mathrm{x}} \mathrm{Me}_{(3-\mathrm{x})}$ ligands: $\operatorname{IE}\left(\mathrm{PPh}_{\mathrm{x}} \mathrm{Me}_{(3-\mathrm{x})}\right)=8.62,8.32,8.23$ and $7.80 \mathrm{eV}$ for $\mathrm{x}=0$ up to $\mathrm{x}=3$, respectively. ${ }^{92}$ This indicates an energy difference between the P coordinated-and lone-pair MO 
energies of $1.22,0.88,0.87$ and $0.90 \mathrm{eV}$ respectively, showing first the largest change upon coordination of the $\mathrm{PMe}_{3}$ ligand and then a similar variation for $\mathrm{PPhMe}_{2}, \mathrm{PPh}_{2} \mathrm{Me}$ and $\mathrm{PPh}_{3}$. This suggests a stronger $\sigma$-donor effect of the $\mathrm{PMe}_{3}$ ligand and a similar effect for the others: $\mathrm{PMe}_{3}>$ $\mathrm{PPhMe}_{2} \approx \mathrm{PPh}_{2} \mathrm{Me} \approx \mathrm{PPh}_{3}$. Calculations confirms as well these energy differences (see SI) and thus the trend for this effect.

The EDA results for the $\mathrm{L}=\mathrm{PPh}_{\mathrm{x}} \mathrm{Me}_{(3-\mathrm{x})}$ sets of ligands are presented in Table 3. The interaction energy $\Delta \mathrm{E}_{\text {int }}$ shows a decrease by increasing the number of phenyl groups from $-40.70 \mathrm{kcal} / \mathrm{mol}$ for $\mathrm{PMe}_{3}$ down to $-33.20 \mathrm{kcal} / \mathrm{mol}$ for $\mathrm{PPh}_{3}$, following the same trend as the adiabatic ionization energies. As expected with the structure of these ligands, the steric interaction ( $\left.\Delta \mathrm{E}_{\text {Pauli }}+\Delta \mathrm{E}_{\text {elstat }}\right)$ between the $\mathrm{Mo}(\mathrm{CO})_{5}$ and $\mathrm{L}$ fragments is playing a non-negligible role: from $7.35 \mathrm{kcal} / \mathrm{mol}$ for the small $\mathrm{PMe}_{3}$ fragment, it raises up to $12.35 \mathrm{kcal} / \mathrm{mol}$ for $\mathrm{PPh}_{3}$. This feature is mostly due to a decreasing $\Delta \mathrm{E}_{\text {elstat }}$ term for large ligands: the overlap between the phosphorous lone-pair electrons and the nucleus of the metal cannot be as efficient as for small ligands (for steric reasons here but not because of the $\mathrm{p}$ character of the $\sigma \mathrm{HOMO}$ of $\mathrm{PX}_{3}$ which is also high in $\mathrm{PPh}_{3}$ (above $50 \%$, see SI)). The orbital contribution to the total attractive bond interaction slightly increases with $\mathrm{x}$ $(35.2 \%$ for $\mathrm{x}=0$ up to $39.6 \%$ for $\mathrm{x}=3$ ). The ETS-NOCV results are given in Table 4 (and the deformation densities in Fig.6 for $\mathrm{PPh}_{3}$, in the SI for the other ligands). They confirm very well the experimental findings: $\mathrm{PMe}_{3}$ appears to be a better $\sigma$-donor ligand compared to $\mathrm{PPhMe}_{2}$, $\mathrm{PPh}_{2} \mathrm{Me}$ and $\mathrm{PPh}_{3}$, as seen by the slightly decreasing $\sigma$-donor contribution ( $73.6 \% \mathrm{vs} 72.7 \%, 71.6 \%$ and $71.2 \%$, respectively). On the other hand, the $\pi$-acceptor part on the total orbital interaction remains stable for all the series: between 13.2 and $13.9 \%$ of the $(\sigma+\pi)$ orbital contribution. The TEPs of these ligands match with these observations: the stretching frequencies $v_{\mathrm{CO}}$ in $\mathrm{Ni}(\mathrm{CO})_{3} \mathrm{~L}$ 
complexes follow this trend: $\mathrm{PMe}_{3}\left(2064 \mathrm{~cm}^{-1}\right)<\operatorname{PPhMe}_{2}\left(2065 \mathrm{~cm}^{-1}\right)<\operatorname{PPhMe}_{2}\left(2067 \mathrm{~cm}^{-1}\right)<$ $\mathrm{PPh}_{3}\left(2069 \mathrm{~cm}^{-1}\right)$, giving $\mathrm{PMe}_{3}$ slightly more $\sigma$-donating than $\mathrm{PPh}_{3}{ }^{90}$

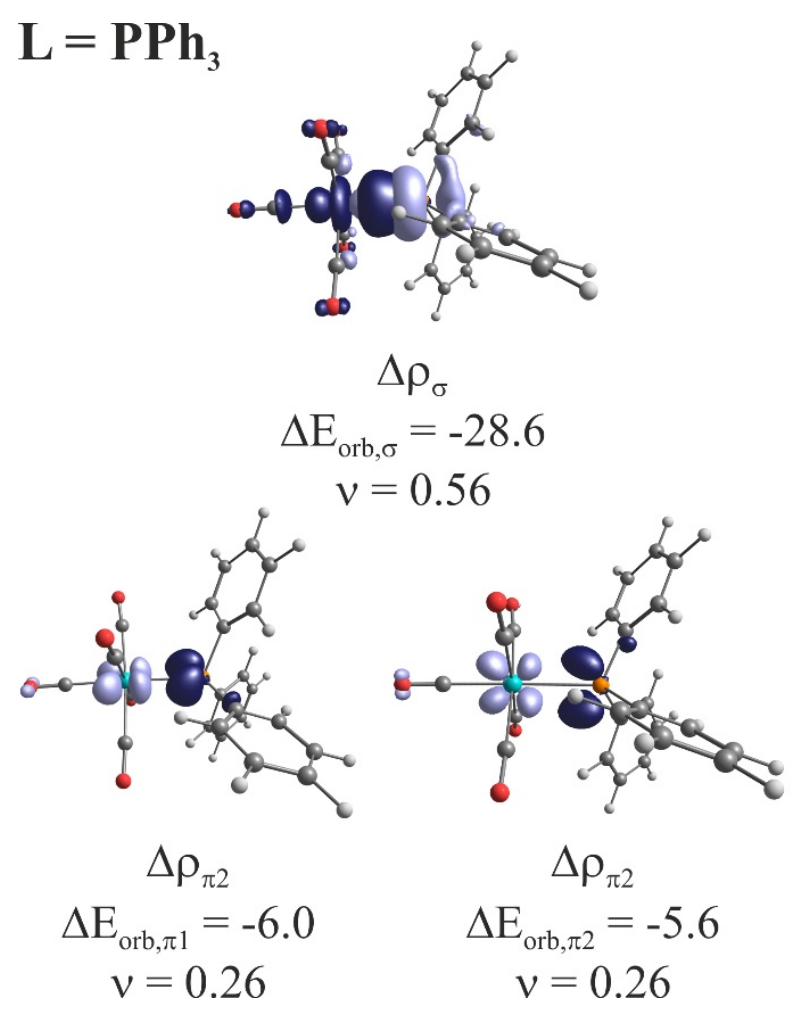

Figure 6. Contours of deformation density $\Delta \rho_{\sigma / \pi}$ connected with the pairs of interacting orbitals in the $\mathrm{Ph}_{3} \mathrm{P}-\mathrm{Mo}(\mathrm{CO})_{5}$ complex. Light purple surfaces represent a loss of electron density and dark blue surfaces, a gain of electron density. The associated orbital interaction energies $\Delta \mathrm{E}_{\text {orb }}$ are given in $\mathrm{kcal} / \mathrm{mol} . v$ is the eigenvalue indicating the size of the charge flow. Isosurface value: 0.0025 a.u.

The last set of ligands studied was the $\mathrm{L} \quad(\mathrm{Pyrl}=$ pyrrolyl, $\mathrm{x}=0-3)$ series. The ion signal was optimized for a temperature between $100^{\circ} \mathrm{C}\left(\mathrm{PPyrl}_{3}\right)$ and $150^{\circ} \mathrm{C}\left(\mathrm{PPh}_{3}\right)$ and resulting SPES are presented in Fig. 7. Whereas the $\mathrm{PPh}_{3}$ complex still has a SPES quite similar to the previous SPES shown (i.e. constituted by a first intense band at ca. $7.7 \mathrm{eV}$ and a smaller one at ca. $8.7 \mathrm{eV}$ ), once the ligand contains at least one pyrrolyl, the SPES changes dramatically to a unique unstructured 

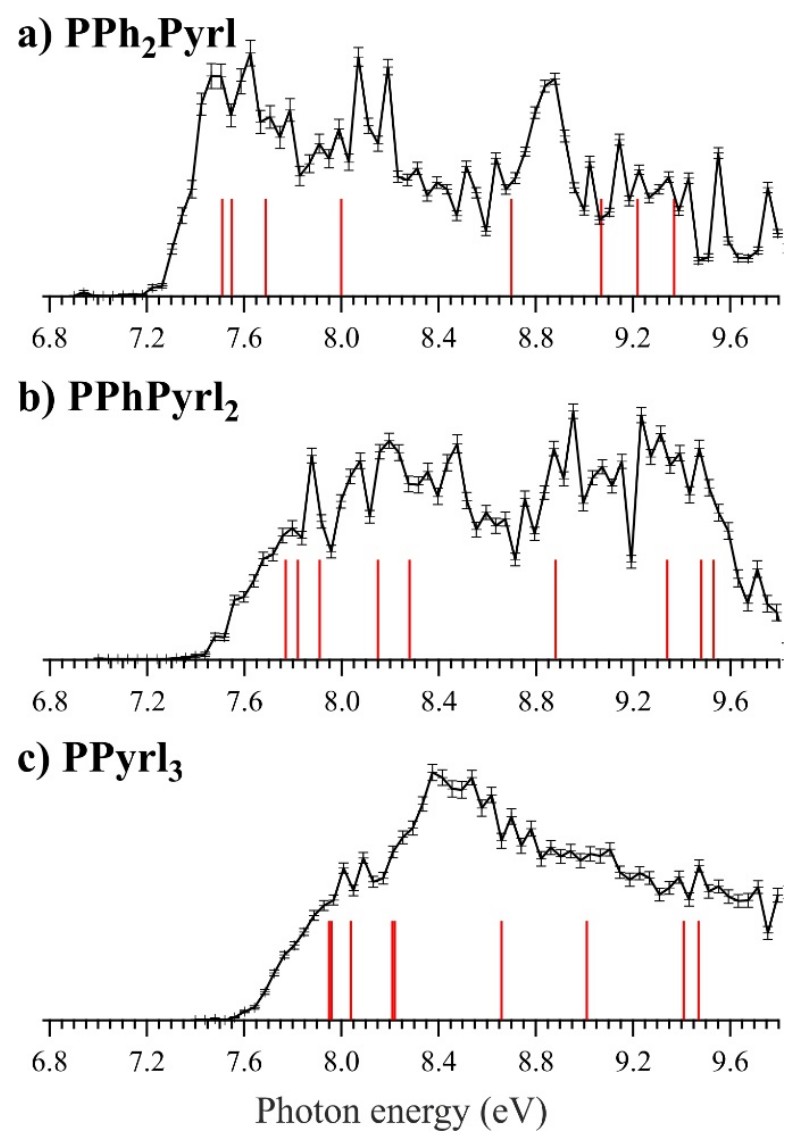

Figure 7. SPES of the $\mathrm{LMo}(\mathrm{CO})_{5}^{+\bullet}$ ions for the $\mathrm{PPh}_{\mathrm{x}} \mathrm{Pyrl}_{(3-\mathrm{x})}$ series recorded in the 6.8-9.7 eV energy range. Red lines represent the calculated energies of the first HOMOs of the neutral complexes

broad band. This feature is explained by considering the MOs involved in the signal: up to 9 HOMOs distributed all over the 7.5-9.8 eV range and presenting a mixing from the orbitals of the metal and of the ligands (see Fig. 8 to visualized the nine first $\mathrm{HOMOs}$ of $\mathrm{Pyrl}_{3} \mathrm{PMo}(\mathrm{CO})_{5}$ and in the SI for the other ligands). From HOMO to HOMO-5, the orbitals are characterized by a contribution of the pyrrolyl groups in addition to the metal $\mathrm{d}$ orbitals. This orbital mixing renders the interpretation of the electronic effects much more complex if not impossible. But reasoning on the adiabatic ionization variation energy still enables to get some insights on the ionization process. 
A clear increase of the IE values is indeed observed by increasing the number of pyrrolyls: from $6.99 \mathrm{eV}$ for $\mathrm{PPh}_{3}$ to $7.59 \mathrm{eV}$ for $\mathrm{PPyrl}_{3}$. As the first HOMOs are not only related to metal orbitals but also to pyrrolyl's, it is thus not straightforward to conclude that the lowest the IE, the largest the global donor effect of the ligand. As stated for $\mathrm{PR}_{3}$ ligands, this argument indeed holds true if the corresponding ejected electron is in the direct metal environment reflecting thus the interaction between the metal and the ligand. Considering the partial NBO charges on the $\mathrm{PX}_{3}$ moiety in the neutral and in the ionized complex indicates an interesting feature. For $\mathrm{PPh}_{3}$, only a slight increase of the electron deficiency on the ligand is observed upon ionization $(+0.312)$ whereas it is very high for PPyrl $3(+0.907)$ (Table 2). This shows that the charge is carried mostly by the ligand for $\mathrm{PPyrl}_{3}$ on $\mathrm{LMo}(\mathrm{CO})_{5}{ }^{+}$and on the metal for $\mathrm{PPh}_{3}$, revealing a $\pi$ (pyrrolyl) ionization and a d (Mo) ionization, respectively (assuming that no electronic rearrangement occurs after ionization). Thus, as the electron is ejected from the ligand (which is, in this case, termed as "non-innocent" ligand), ${ }^{93-94}$ one can assume that the less interaction the ligand has with the metal, then the more density remains on it which accordingly increases its stability and therefore its ionization energy. This would thus indicate that $\mathrm{PPyrl}_{3}$ is less globally donating than $\mathrm{PPh}_{3}$ because its $\mathrm{IE}_{\text {ad }}$ is higher in energy. This trend is consistent with the known very strong electron-acceptor effect of pyrrolylcontaining phosphine ligands which counterbalances any possible donating effect, ${ }^{95}$ and with the NBO charge analysis showing a slight decreased of the electron deficiency of the ligand by increasing the number of pyrrolyls (see SI). Considering now the MO shapes and energies in more details reveals that the orbitals accounting for the SPES can be roughly separated in three groups. The first one located below to $8.4 \mathrm{eV}$ is constituted by orbitals with a combination of metal $\mathrm{d}$ and $\pi$ (pyrrolyl) character (HOMO to HOMO-5 for PPyrl 3 , Fig.8). The second one concerns one orbital at $8.62,8.70,8.88$ and $9.01 \mathrm{eV}$ for ligand with zero to three pyrrolyls, respectively. This orbital is 
the only one which exhibits in part a Mo-P $\sigma$ character (HOMO-6 for PPyrl 3 ). And finally, the last group is composed by orbitals with a $\pi$ (phenyl) and $\pi$ (pyrrolyl) contributions (HOMO-7 and HOMO-8 for $\mathrm{PPyrl}_{3}$ ). This analysis of the MOs repartition helps us to derive at least one property for this set of ligands: the calculated $\sigma$ ionization is indeed distinctly decreasing by lowering the number of pyrrolyls in the $\mathrm{PPh}_{\mathrm{x}} \mathrm{Pyrl}_{(3-\mathrm{x})}$ set and comparing these values with the calculated $\mathrm{P}$ lone pair ionization in uncoordinated ligand shows that the energy difference is decreasing with the number of pyrrolyls (see SI) giving thus $\mathrm{PPyrl}_{3}$ less $\sigma$-donating than $\mathrm{PPh}_{3}$. Furthermore, comparing the $\pi$-acceptor effect of the different ligands is not possible for this series of ligands because of the high mixing between the metal orbitals and the ligand orbitals.

$$
\mathbf{L}=\mathbf{P P y r l}_{3}
$$

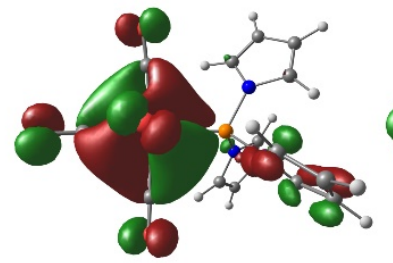

HOMO

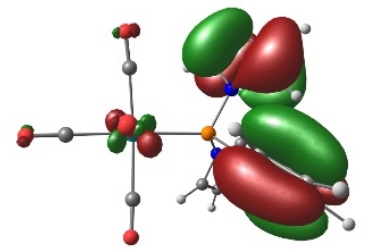

HOMO-3

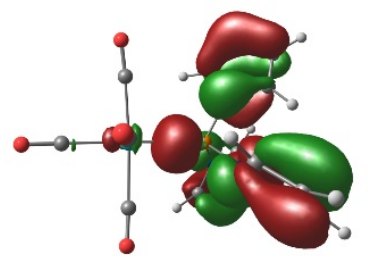

HOMO-6

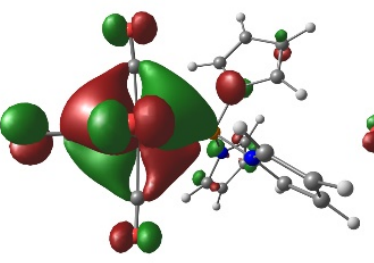

HOMO-1

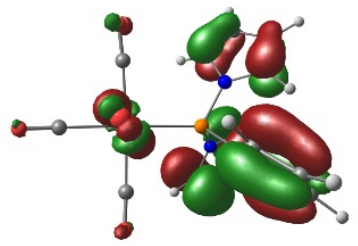

HOMO-4

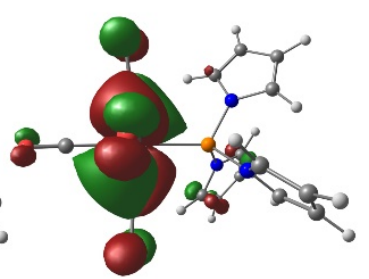

HOMO-2

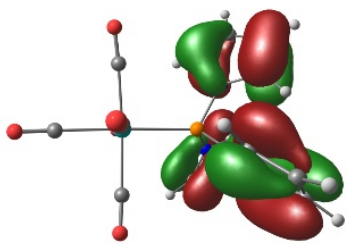

HOMO-5

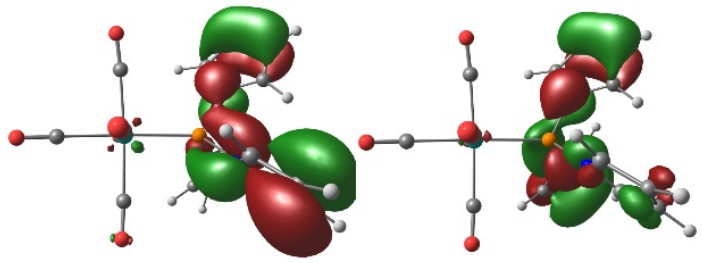

HOMO-7

Figure 8. Kohn-Sham orbitals of $\mathrm{Pyrl}_{3} \mathrm{PMo}(\mathrm{CO})_{5}$ obtained at the $\mathrm{LC}-\omega \mathrm{PBEh} / \mathrm{Def} 2-\mathrm{TZVP}$ level of theory. Isosurface value: 0.03 a.u. 


\section{$\mathbf{L}=$ PPyrl $_{3}$}

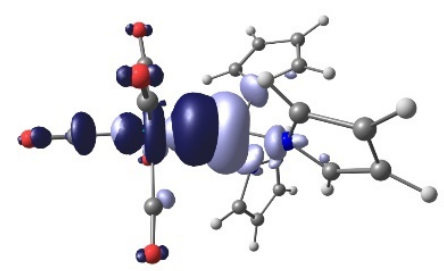

$\Delta \rho_{\sigma}$

$\Delta \mathrm{E}_{\text {orb }, \sigma}=-27.2$

$v=0.51$

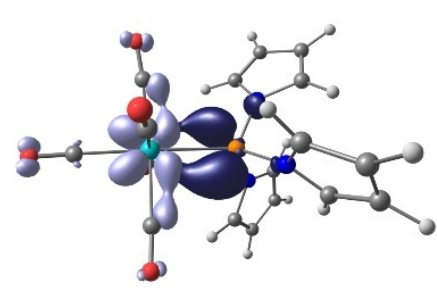

$\Delta \rho_{\pi 2}$

$\Delta \mathrm{E}_{\text {orb }, \pi 1}=-9.5$

$v=0.33$

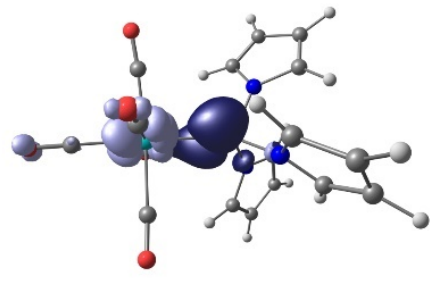

$\Delta \rho_{\pi 2}$

$\Delta \mathrm{E}_{\text {orb }, \pi 2}=-9.4$

$v=0.33$

Figure 9. Contours of deformation density $\Delta \rho_{\sigma / \pi}$ connected with the pairs of interacting orbitals in the $\mathrm{Pyrl}_{3} \mathrm{P}-\mathrm{Mo}(\mathrm{CO})_{5}$ complex. Light purple surfaces represent a loss of electron density and dark blue surfaces, a gain of electron density. The associated orbital interaction energies $\Delta \mathrm{E}_{\text {orb }}$ are given in $\mathrm{kcal} / \mathrm{mol} . v$ is the eigenvalue indicating the size of the charge flow. Isosurface value: 0.0025 a.u.

The EDA results for this series are displayed in Table 3. Not surprisingly, the electrostatic interaction remains the same (between -69.6 and $-70.31 \mathrm{kcal} / \mathrm{mol}$ ) along the series because of similar steric properties and $\mathrm{p}$ character on the $\sigma \mathrm{MO}$ of $\mathrm{PX}_{3}$ (see SI). A small variation is observed for the interaction energy: it slightly decreases from $\mathrm{PPh}_{3}$ to $\mathrm{PPyrl}_{3}$. On the contrary to the other ligands sets studied in this work, the trend observed in $\Delta \mathrm{E}_{\text {int }}$ is the opposite as that observed for $\mathrm{IE}_{\mathrm{ad}}$ for this series. This feature will be discussed further. Only the Pauli interaction seems to be more influenced by the ligand change: it ranges from $81.97 \mathrm{kcal} / \mathrm{mol}$, for $\mathrm{PPh}_{3}$ up to $90.16 \mathrm{kcal} / \mathrm{mol}$ 
for $\mathrm{PPyrl}_{3}$. The deformation densities contributions to the orbital interaction are informative as they provides an evaluation of the $\sigma$-donor and $\pi$-acceptor effects of the ligands that were not obtained by experiment (Table 4 and Fig. 9 for the deformation densities of $\mathrm{PPyrl}_{3}$, in the SI for the other ligands). The strong electron-withdrawing character of the N-pyrrolylphosphines appears with the large $\Delta \mathrm{E}_{\mathrm{orb}, \pi 1}$ and $\Delta \mathrm{E}_{\mathrm{orb}, \pi 2}$ contributions to the total orbital interaction (up to $41 \%$ for $\mathrm{PPyrl}_{3}$ with a significant NOCV eigenvalue of 0.66 vs 0.51 for $\mathrm{PPh}_{3}$ (Fig. 9 and S2)), giving the following trend for the $\pi$-acceptor character of the ligand: $\mathrm{PPyrl}_{3}>\mathrm{PPyrl}_{2} \mathrm{Ph}>\mathrm{PPyrlPh}_{2}>\mathrm{PPh}_{3}$. On the contrary, the $\sigma$-donor part is decreasing with the number of pyrrolyls increasing as confirmed by the MOs analysis. The Tolman analysis of N-pyrrolylphosphine ligands is consistent with these results, giving the following $v_{c o}$ stretching frequencies for $\mathrm{RhCl}(\mathrm{CO}) \mathrm{L}_{2}$ complexes: $1965 \mathrm{~cm}^{-1}\left(\mathrm{PPh}_{3}\right), 1992 \mathrm{~cm}^{-1}\left(\mathrm{PPyrlPh}_{2}\right), 2007 \mathrm{~cm}^{-1}\left(\mathrm{PPyrl}_{2} \mathrm{Ph}\right)$ and $2024 \mathrm{~cm}^{-1}\left(\operatorname{PPyrl}_{3}\right){ }^{95}$

Finally, the last point that we would like to address in this study concerns the correlation that may exist between $\mathrm{IE}_{\mathrm{ad}}$ and the interaction energy $\Delta \mathrm{E}_{\text {int }}$ obtained from EDA. Whereas the latter indicates the strength of the interaction between the ligand and the metal, the former gives an assessment of the enrichment of the metal through the interaction with the ligand: the more net donating the ligand is, the higher $\mathrm{IE}_{\text {ad }}$ the complex has, because of the stabilization provided on this metal (assuming an ionization occurring on the $\mathrm{d}$ orbital of Mo). For the $\mathrm{L}=\mathrm{PR}_{3}$ and $\mathrm{L}=$ $\mathrm{PPh}_{\mathrm{x}} \mathrm{Me}_{(3-\mathrm{x})}$ sets of ligands, we have observed the same trend for both terms: for the most donating ligands, $\mathrm{IE}_{\mathrm{ad}}$ and $\Delta \mathrm{E}_{\mathrm{int}}$ were the largest. On the other hand, this trend was reversed for the $\mathrm{L}=$ $\mathrm{PPh}_{x} \operatorname{Pyrl}_{(3-\mathrm{x})}$ ligands: the less donating ligand exhibits the higher $\mathrm{IE}_{\text {ad }}$ and the smaller $\Delta \mathrm{E}_{\text {int. }}$ In this case, we explain this discrepancy by the fact that ionization may also be occurring directly on the $\pi$ orbitals of the ligand and not to the $\mathrm{d}$ MO of the metal ("non-innocent" ligands). As suggested by a reviewer, we have considered the average local ionization energy (ALIE) of the complexes 
to reinforce this assumption. ALIE is defined as the sum over orbital electron densities times absolute orbital energies and divided by the total electron density. ${ }^{96}$ It helps unveiling molecular regions the most prone to lose an electron. In Fig. S3, the ALIE mapped molecular isosurfaces of the $\mathrm{L}=\mathrm{PMe}_{3}, \mathrm{PPh}_{3}$ and $\mathrm{PPyrl}_{3}$ complexes are displayed. The blue area where the electrons are the most weakly bond is concentrated for all three ligands in the metal region but it is also present in the ligand, principally for $\mathrm{L}=\mathrm{PPyrl}_{3}$ which confirms our experimental findings. The correlation obtained between the $\mathrm{IE}_{\mathrm{ad}}$ and $\Delta \mathrm{E}_{\text {int }}$ terms is illustrated in Figure 10. Two rather good linear correlation appear: the first one for the $\mathrm{L}=\mathrm{PR}_{3}$ and $\mathrm{L}=\mathrm{PPh}_{\mathrm{x}} \mathrm{Me}_{(3-\mathrm{x})}$ sets of ligands (red squares, $\mathrm{r}^{2}=0.91$ ) and the second one for the $\mathrm{L}=\mathrm{PPh}_{\mathrm{x}} \mathrm{Pyrl}_{(3-\mathrm{x})}$ ligands (blue diamonds, $\mathrm{r}^{2}=0.94$ ). Although many factors certainly influence the interaction between a metal and a ligand, the correlation found here between these two parameters seems to us to be an interesting and promising trail to get an easy and rapid experimental evaluation of net donating ligand effects and also on the intrinsic character (innocent/non innocent) of the ligand.

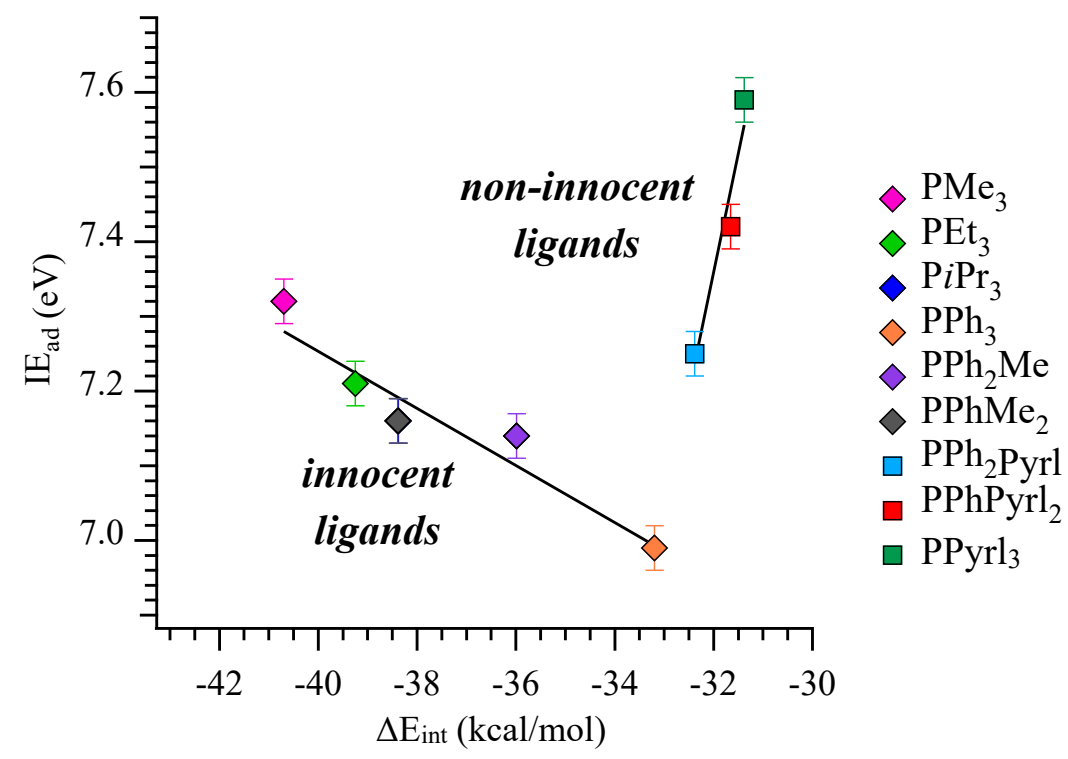

Figure 10. Correlation plots between $\mathrm{IE}_{\mathrm{ad}}$ and $\Delta \mathrm{E}_{\text {int }}$ (values given in Tables 1 and 2) for all ligands studied. Note that the points for $\mathrm{L}=\mathrm{P} i \mathrm{Pr}_{3}$ and $\mathrm{L}=\mathrm{PPhMe}_{2}$ are superimposed. 


\section{Conclusions}

We have presented here a detailed study on the photoionization process of $\mathrm{X}_{3} \mathrm{PMo}(\mathrm{CO})_{5}$ complexes with various $\mathrm{PX}_{3}$ ligands. Our interest was to determine if VUV spectroscopy was a suitable techniques for the experimental study of electronic properties of different phosphine ligands and separation of their $\pi$-acceptor and $\sigma$-donor effect. Experimental data obtained from a state-of-the-art experimental setup were confronted to the EDA method which is known to be very well adapted for ligands effect description. Three sets of ligands have been considered. The first one, the $\mathrm{PR}_{3}$ set $(\mathrm{R}=$ alkyl), delivered SPES which could show that by increasing the alkyl size, the ligands have i) small decreasing $\pi$-acceptor properties, ii) increased $\sigma$-donor ability and iii-) an lower global donor electronic effect. For the second ligands set $\left(\mathrm{PPh}_{\mathrm{x}} \mathrm{Me}_{(3-\mathrm{x})}\right)$, SPES let us deduce that the $\pi$-acceptor effect remains unchanged in the series and that the same $\mathrm{PPh}_{3}>\mathrm{PPh}_{2} \mathrm{Me}>$ $\mathrm{PPhMe}_{2}>\mathrm{PMe}_{3}$ trend is observed in terms of $\sigma$-donor and global electronic effect. Finally, the last set to be studied was the $\mathrm{PPh}_{\mathrm{x}} \mathrm{Pyrl}_{(3-\mathrm{x})}$ set whose SPES were dramatically different compared to the other ligands because of a high contribution of $\pi$ (pyrrolyls) orbitals in the spectrum energy range. These spectra could thus not been interpreted in the same way as for the other ligands. We could however confirm the strong electron-acceptor and the poor donor ability of the $\mathrm{PPyrl}_{3}$ ligand compared to $\mathrm{PPh}_{3}$. An increased energy resolution could maybe help to observe better structured bands for these ligands and thus get more insights on the experimental evaluation of the $\sigma$-donor and $\pi$-acceptor effects of this set of ligands.

Comparison of these experimental results with EDA calculations shows an excellent agreement. The same trends and conclusions indeed arise from these two methods. The perspectives offered by such a joint experimental and theoretical work are very broad. Many very elaborated theoretical approaches have indeed been developed to describe ligand effects. But most of them also suffer 
from the lack of experimental data to confirm their findings. On the other hand, the interpretation and analysis of the experimental spectra is greatly improved by using a theoretical approach such as EDA. The aim of the experimental part of this work was indeed not to deliver a complete description of the metal-ligand bonding as it can be done by theory. A description of the electronic structure of the complex was done and could thus give access to an evaluation of orbital description of the metal-ligand interaction. Other interaction terms (electrostatic, steric,...) terms were provided by theory.

Finally, a correlation could be found between the measure adiabatic ionization energies ( $\mathrm{IE}_{\mathrm{ad}}$ ) and the interaction energies ( $\left.\Delta \mathrm{E}_{\text {int }}\right)$ obtained from EDA. Depending on the ionization site of the complex (e.g. either on the $\mathrm{d}$ orbital of the metal or on the ligand's orbital), $\mathrm{IE}_{\text {ad }}$ and $\Delta \mathrm{E}_{\text {int }}$ follow the same or the opposite trend. To our knowledge, it is the first time that such a correlation is evidenced. It opens interesting perspectives on the possibility to predict the innocent/non-innocent character of ligands which is known to orientate the chemistry of complexes. This correlation will be investigated further on other ligands and metals.

\section{Supporting Information}

Synthetic procedure; NMR spectra; computational data; DFT energies; ETS-NOCV; ALIE; cartesian coordinates

\section{Acknowledgments}

We would like to dedicated this work on the memory of Ridha Elattar, a brilliant young researcher of our group who passed away this year.

This work was supported by the ANR ELEEM2 project, grant ANR-13-BS07-0001 of the French Agence Nationale de la Recherche (postdoc funding of DG) and LABEX MiChem. The theoretical 
work was performed using HPC resources from GENCI-CINES (Grant AP010809172) and of the HPCaVe centre at UPMC-Sorbonne University. The authors acknowledge the technical support of the DESIRS beamline staff, in particular Dusan Bozanic and Xiaofeng Tang, and the general staff of SOLEIL for smoothly running the facility. HD deeply thanks Gustavo Garcia (SOLEIL) for the help with data analysis and interpretation as well as Thomas Körzdörfer (Postdam University) for fruitful recommendation on the use of IP-tuned LC- $\omega$ PBEh method and G. Frison for the introduction to EDA calculations. W. Xing and A. Guerault are also acknowledged for taking part to the experiments.

\section{References}

1. Constable, E. C. In Metals and Ligand Reactivity. Constable, E. C., Ed.; John Wiley and Sons: 2005 ; p 22-45.

2. The Development of Catalysis: A History of Key Processes and Personas in Catalytic Science and Technology. Zecchina, A.; Califano, S., Eds.; John Wiley and Sons, 2017.

3. Chatt, J.; Duncanson, L. A. 586. Olefin Co-Ordination Compounds. Part Iii. Infra-Red Spectra and Structure: Attempted Preparation of Acetylene Complexes. J. Chem. Soc. 1953, 2939-2947.

4. Dewar, M. J. S. A Review of П Complex Theory. Bull. Soc. Chim. Fr. 1951, 18, C79.

5. Introduction to Coordination Chemistry. Lawrance, G. A., Ed.; John Wiley and Sons: Chichester, UK, 2012.

6. Tolman, C. A. Steric Effects of Phosphorus Ligands in Organometallic Chemistry and Homogeneous Catalysis. Chem. Rev. 1977, 77, 313-348.

7. Perrin, L.; Clot, E.; Eisenstein, O.; Loch, J.; Crabtree, R. H. Computed Ligand Electronic Parameters from Quantum Chemistry and Their Relation to Tolman Parameters, Lever Parameters, and Hammett Constants. Inorg. Chem. 2001, 40, 5806-5811.

8. Cooney, K. D.; Cundari, T. R.; Hoffman, N. W.; Pittard, K. A.; Temple, M. D.; Zhao, Y. A Priori Assessment of the Stereoelectronic Profile of Phosphines and Phosphites. J. Am. Chem. Soc. 2003, 125, 4318-4324.

9. Kalescky, R.; Kraka, E.; Cremer, D. New Approach to Tolman's Electronic Parameter Based on Local Vibrational Modes. Inorg. Chem. 2014, 53, 478-495.

10. Durand, D. J.; Fey, N. Computational Ligand Descriptors for Catalyst Design. Chem. Rev. 2019, 119, 6561-6594.

11. Frenking, G. In The Eda Perspective of Chemical Bonding. Frenking, G.; Shaik, S., Eds.; Wiley-VCH: 2014; p 121-157.

12. Mitoraj, M.; Michalak, A. Natural Orbitals for Chemical Valence as Descriptors of Chemical Bonding in Transition Metal Complexes. J. Mol. Model. 2007, 13, 347-55. 
13. Ardizzoia, G. A.; Brenna, S. Interpretation of Tolman Electronic Parameters in the Light of Natural Orbitals for Chemical Valence. PCCP 2017, 19, 5971-5978.

14. Antonova, N. S.; Carbó, J. J.; Poblet, J. M. Quantifying the Donor-Acceptor Properties of Phosphine and N-Heterocyclic Carbene Ligands in Grubbs' Catalysts Using a Modified Eda Procedure Based on Orbital Deletion. Organometallics 2009, 28, 4283-4287.

15. Landis, C. R.; Weinhold, F. In The Chemical Bond. Frenking, G.; Shaik, S., Eds.; WileyVCH: 2014; p 91-120.

16. Leyssens, T.; Peeters, D.; Orpen, A. G.; Harvey, J. N. How Important Is Metal-Ligand BackBonding toward Yx3 Ligands (Y = N, P, C, Si)? An Nbo Analysis. Organometallics 2007, 26, 2637-2645.

17. Ozimiński, W. P.; Dobrowolski, J. C. $\Sigma$ - and П-Electron Contributions to the Substituent Effect: Natural Population Analysis. J. Phys. Org. Chem. 2009, 22, 769-778.

18. Suresh, C. H.; Koga, N. Quantifying the Electronic Effect of Substituted Phosphine Ligands Via Molecular Electrostatic Potential. Inorg. Chem. 2002, 41, 1573-1578.

19. Remya, G. S.; Suresh, C. H. Substituent Effect Parameters: Extending the Applications to Organometallic Chemistry. ChemPhysChem 2020, 21, 1028-1035.

20. Wang, S. P.; Richmond, M. G.; Schwartz, M. Nmr Evidence for the Existence of A .Pi.Accepting $\mathrm{Pme}_{3}$ Ligand. Estimates of the Magnitude Of .Pi. Effects of W1(Co) ${ }_{5}$ Complexes. J. Am. Chem. Soc. 1992, 114, 7595-7596.

21. Mampa, R. M.; Fernandes, M. A.; Carlton, L. Iron-57 Nmr and Structural Study of [Fe(H5$\left.\mathrm{Cp})\left(\mathrm{Snph}_{3}\right)(\mathrm{Co})\left(\mathrm{Pr}_{3}\right)\right]\left(\mathrm{Pr}_{3}=\right.$ Phosphine, Phosphite). Separation of Steric and Electronic $\Sigma$ and $\Pi$ Effects. Organometallics 2014, 33, 3283-3299.

22. Green, J. C. Variable Photon Energy Photoelectron Spectroscopy of Transition Metal Molecules. Acc. Chem. Res. 1994, 27, 131-137.

23. Weiner, M. A.; Lattman, M.; Grim, S. O. Ultraviolet Photoelectron Spectra of Some Substituted Triarylphosphines. J. Org. Chem. 1975, 40, 1292-1294.

24. Green, J. C. In Comprehensive Organometallic Chemistry Iii. Mingos, D. M. P.; Crabtree, R. H., Eds.; Elsevier: Oxford, 2007; p 381-406.

25. Lichtenberger, D. L.; Fenske, R. F. Assignment of the Photoelectron Spectra of Methylpentacarbonylmanganese and Perfluoromethylpentacarbonylmanganese. Inorg. Chem. 1974, 13, 486-488.

26. Lichtenberger, D. L.; Sarapu, A. C.; Fenske, R. F. Photoelectron Spectra and Electronic Structure of Pentacarbonylmanganese Halides. Inorg. Chem. 1973, 12, 702-705.

27. Photoelectron Spectroscopy (Second Edition). Eland, J. H. D., Ed.; Butterworths \& Co Ltd: 1984.

28. Lichtenberger, D. L.; Copenhaver, A. S. In Bonding Energetics in Organometallic Compounds. Marks, T. J., Ed. ACS: 1990; Vol. 428, p 84-99.

29. Lichtenberger, D. L.; Gruhn, N. E.; Renshaw, S. K. Relative Bonding Capabilities of Molecules to Metals as Measured by Gas-Phase Photoelectron Spectroscopy. J. Mol. Struct. 1997, 405, 79-86.

30. Lichtenberger, D. L.; Jatcko, M. E. Electronic Structure of Monodentate-Coordinated Diphosphine Complexes. Photoelectron Spectra of Pentacarbonylmethylene Bis(Dimethyl Phosphine)Molybdenum and Pentacarbonylethylene Bis(Dimethyl Phosphine)Molybdenum. Inorg. Chem. 1992, 31, 451-455.

31. Lichtenberger, D. L.; Jatcko, M. E. Steric and Electronic Balance in Metal-Phosphine Coordination: The Phosphine Twist. J. Coord. Chem. 1994, 32, 79-101. 
32. Lichtenberger, D. L.; Kellogg, G. E. Experimental Quantum Chemistry: Photoelectron Spectroscopy of Organotransition-Metal Complexes. Acc. Chem. Res. 1987, 20, 379-387.

33. Lichtenberger, D. L.; Kellogg, G. E.; Landis, G. H. Principles of Electronic Structure in Transition Metal Complexes. Additive Ligand Electronic Effects and Core-Valence Ionization Correlations for $\mathrm{Mo}(\mathrm{Co})_{6-\mathrm{N}}\left(\mathrm{Pme}_{3}\right)_{\mathrm{N}}$ Where $\mathrm{N}=0,1,2,3$. J. Chem. Phys. 1985, 83, 2759-2768.

34. Golovin, M. N.; Rahman, M. M.; Belmonte, J. E.; Giering, W. P. Quantitative Separation of $\Sigma$ - and П-Components of Transition Metal-Phosphorus Bonding and the Application of Ligand Effects in Organometallic Chemistry. Organometallics 1985, 4, 1981-1991.

35. Wilson, M. R.; Prock, A.; Giering, W. P.; Fernandez, A. L.; Haar, C. M.; Nolan, S. P.; Foxman, B. M. П Effects Involving $\mathrm{Rh}-\mathrm{Pz}_{3}$ Compounds. The Quantitative Analysis of Ligand Effects (Qale) Organometallics 2002, 21, 2758-2763.

36. Fernandez, A.; Reyes, C.; YingLee, T.; Prock, A.; Giering, W. P.; Haar, C. M.; Nolan, S. P. Assessing the Stereoelectronic Properties of Pyrrolyl Phosphines and Related Ligands. The Quantitative Analysis of Ligand Effects (Qale). J. Chem. Soc. Perk. Trans. 2 2000, 7, 13491357.

37. Coll, D. S.; Vidal, A. B.; Rodríguez, J. A.; Ocando-Mavárez, E.; Añez, R.; Sierraalta, A. A Simple Method for the Determination of the Tolman Electronic Parameter of Different Phosphorus Containing Ligands, by Means of the Average Local Ionization Energy. Inorg. Chim. Acta 2015, 436, 163-168.

38. Kevin, H. S. Monodentate Trialkylphosphines: Privileged Ligands in Metal-Catalyzed Crosscoupling Reactions. Curr. Org. Chem. 2020, 24, 231-264.

39. Fleming, J. T.; Higham, L. J. Primary Phosphine Chemistry. Coord. Chem. Rev. 2015, $297-$ 298, 127-145.

40. Phosphorus(Iii) Ligands in Homogeneous Catalysis: Design and Synthesis. Kamer, P. C. J.; van Leeuwen, P. W. N. M., Eds.; Wiley Chichester, U.K, 2012.

41. Reber, A. C.; Bista, D.; Chauhan, V.; Khanna, S. N. Transforming Redox Properties of Clusters Using Phosphine Ligands. J. Phys. Chem. C 2019, 123, 8983-8989.

42. Hanf, S.; Colebatch, A. L.; Stehr, P.; García-Rodríguez, R.; Hey-Hawkins, E.; Wright, D. S. An Experimental and Theoretical Study of the Coordination and Donor Properties of Tris2-Pyridyl-Phosphine Ligands. Dalton Trans. 2020, 49, 5312-5322.

43. Mitoraj, M. P.; Michalak, A. $\Sigma$-Donor and П-Acceptor Properties of Phosphorus Ligands: An Insight from the Natural Orbitals for Chemical Valence. Inorg. Chem. 2010, 49, 578582.

44. Bancroft, G. M.; Dignard-Bailey, L.; Puddephatt, R. J. Spectroscopic Study of the Effect of Methyl and Phenyl Substituents on the Basicity of Phosphine Ligands in Tungsten Carbonyl Derivatives. Inorg. Chem. 1986, 25, 3675-3680.

45. Bursten, B. E.; Darensbourg, D. J.; Kellogg, G. E.; Lichtenberger, D. L. Ligand Additivity in the Valence Photoelectron Spectroscopy of Phosphine-Substituted Molybdenum Carbonyls. Inorg. Chem. 1984, 23, 4361-4365.

46. Clarke, M. L.; Frew, J. J. R. In Organometallic Chemistry. Fairlamb, I. J. S.; Lynam, J. M., Eds.; RSC: 2009; Vol. 35, p 19-46.

47. Kühl, O. Predicting the Net Donating Ability of Phosphines-Do We Need Sophisticated Theoretical Methods? Coord. Chem. Rev. 2005, 249, 693-704.

48. Nahon, L.; Oliveira, N. d.; Garcia, G. A.; Gil, J.-F.; Pilette, B.; Marcouillé, O.; Lagarde, B.; Polack, F. Desirs: A State-of-the-Art Vuv Beamline Featuring High Resolution and Variable 
Polarization for Spectroscopy and Dichroism at Soleil J. Synchrotron Radiat. 2012, 59, 508520.

49. Marcouillé, O.; Brunelle, P.; Chubar, O.; Marteau, F.; Massal, M.; Nahon, L.; Tavakoli, K.; Veteran, J.; Filhol, J. M. In Design, Construction and Magnetic Measurements of the Hu640 (Ophelie2) Undulator Dedicated to the Desirs Vuv Beamline at Soleil, Synchrotron Radiation Instrumentation: Ninth International Conference on Synchrotron Radiation Instrumentation, 2007; AIP Conference Proceedings, 2007; pp 311-314.

50. Nahon, L.; Alcaraz, C.; Marlats, J. L.; Lagarde, B.; Polack, F.; Thissen, R.; Lepère, D.; Ito, K. Very High Spectral Resolution Obtained with Su5: A Vacuum Ultraviolet UndulatorBased Beamline at Super-Aco. Rev. Sci. Instrum. 2001, 72, 1320-1329.

51. Mercier, B.; Compin, M.; Prevost, C.; Bellec, G.; Thissen, R.; Dutuit, O.; Nahon, L. Experimental and Theoretical Study of a Differentially Pumped Absorption Gas Cell Used as a Low Energy-Pass Filter in the Vacuum Ultraviolet Photon Energy Range. J. Vac. Sci. Technol. A 2000, 18, 2533-2541.

52. Chan, W. F.; Cooper, G.; Guo, X.; Burton, G. R.; Brion, C. E. Absolute Optical Oscillator Strengths for the Electronic Excitation of Atoms at High Resolution. Iii. The Photoabsorption of Argon, Krypton, and Xenon. Phys. Rev. A 1992, 46, 149-171.

53. Tang, X.; Garcia, G. A.; Gil, J.-F.; Nahon, L. Vacuum Upgrade and Enhanced Performances of the Double Imaging Electron/Ion Coincidence End-Station at the Vacuum Ultraviolet Beamline Desirs. Rev. Sci. Instrum. 2015, 86, 123108.

54. Garcia, G. A.; Cunha de Miranda, B. K.; Tia, M.; Daly, S.; Nahon, L. Delicious Iii: A Multipurpose Double Imaging Particle Coincidence Spectrometer for Gas Phase Vacuum Ultraviolet Photodynamics Studies. Rev. Sci. Instrum. 2013, 84, 053112-053111.

55. Garcia, G. A.; Nahon, L.; Powis, I. Two-Dimensional Charged Particle Image Inversion Using a Polar Basis Function Expansion. Rev. Sci. Instrum. 2004, 75, 4989.

56. Lichtenberger, D. L. Development of Theoretical and Helium(I) Photoelectron Methods for the Determination and Interpretation of the Electronic Structure of Large Molecules. Applications to Transition Metal Complexes. Ph.D. Dissertation, University of Wisconsin, Madison, Wis., 1974.

57. Frisch, M. J.; Trucks, G. W.; Schlegel, H. B.; Scuseria, G. E.; Robb, M. A.; Cheeseman, J. R.; Scalmani, G.; Barone, V.; Mennucci, B.; Petersson, G. A., et al. Gaussian 09, Revision D.01; Gaussian, Inc.: Wallingford, CT, 2013.

58. Adamo, C.; Barone, V. Toward Reliable Density Functional Methods without Adjustable Parameters: The Pbe0 Model. J. Chem. Phys. 1999, 110, 6158-6170.

59. Perdew, J. P.; Ernzerhof, M.; Burke, K. Rationale for Mixing Exact Exchange with Density Functional Approximations. J. Chem. Phys. 1996, 105, 9982-9985.

60. Schaefer, A.; Huber, C.; Ahlrichs, R. Fully Optimized Contracted Gaussian Basis Sets of Triple Zeta Valence Quality for Atoms Li to Kr. J. Chem. Phys. 1994, 100, 5829-5835.

61. Rohrdanz, M. A.; Martins, K. M.; Herbert, J. M. A Long-Range-Corrected Density Functional That Performs Well for Both Ground-State Properties and Time-Dependent Density Functional Theory Excitation Energies, Including Charge-Transfer Excited States. J. Chem. Phys. 2009, 130, 054112.

62. Gallandi, L.; Marom, N.; Rinke, P.; Körzdörfer, T. Accurate Ionization Potentials and Electron Affinities of Acceptor Molecules Ii: Non-Empirically Tuned Long-Range Corrected Hybrid Functionals. J. Chem. Theory Comput. 2016, 12, 605-614. 
63. Zhang, G.; Musgrave, C. B. Comparison of Dft Methods for Molecular Orbital Eigenvalue Calculations. J. Phys. Chem. A 2007, 111, 1554-1561.

64. Zhan, C.-G.; Nichols, J. A.; Dixon, D. A. Ionization Potential, Electron Affinity, Electronegativity, Hardness, and Electron Excitation Energy: Molecular Properties from Density Functional Theory Orbital Energies. J. Phys. Chem. A 2003, 107, 4184-4195.

65. Gengeliczki, Z.; Pongor, C. I.; Sztáray, B. Assigning Photoelectron Spectra of Transition Metal Organometallic Complexes on the Basis of Kohn-Sham Orbital Energies. Organometallics 2006, 25, 2553-2560.

66. Ziegler, T.; Rauk, A. A Theoretical Study of the Ethylene-Metal Bond in Complexes between Copper(1+), Silver(1+), Gold(1+), Platinum(0) or Platinum(2+) and Ethylene, Based on the Hartree-Fock-Slater Transition-State Method. Inorg. Chem. 1979, 18, 15581565.

67. Kitaura, K.; Morokuma, K. A New Energy Decomposition Scheme for Molecular Interactions within the Hartree-Fock Approximation. Int. J. Quantum Chem. 1976, 10, 325340.

68. Zhao, L.; von Hopffgarten, M.; Andrada, D. M.; Frenking, G. Energy Decomposition Analysis. WIRES Comput. Mol. Sci. 2018, 8, e1345.

69. Ziegler, T.; Rauk, A. On the Calculation of Bonding Energies by the Hartree Fock Slater Method. Theor. Chim. Acta 1977, 46, 1-10.

70. te Velde, G.; Bickelhaupt, F. M.; Baerends, E. J.; Fonseca Guerra, C.; van Gisbergen, S. J. A.; Snijders, J. G.; Ziegler, T. Chemistry with Adf. J. Comput. Chem. 2001, 22, 931-967.

71. Becke, A. D. Density-Functional Exchange-Energy Approximation with Correct Asymptotic Behavior. Phys. Rev. A 1988, 38, 3098-3100.

72. Grimme, S.; Antony, J.; Ehrlich, S.; Krieg, H. A Consistent and Accurate Ab Initio Parametrization of Density Functional Dispersion Correction (Dft-D) for the 94 Elements H-Pu. J. Chem. Phys. 2010, 132, 154104.

73. Dunning, T. H. Gaussian Basis Functions for Use in Molecular Calculations. Iii. Contraction of (10s6p) Atomic Basis Sets for the First-Row Atoms. J. Chem. Phys. 1971, 55, 716-723.

74. Faas, S.; Snijders, J. G.; van Lenthe, J. H.; van Lenthe, E.; Baerends, E. J. The Zora Formalism Applied to the Dirac-Fock Equation. Chem. Phys. Lett. 1995, 246, 632-640.

75. Mitoraj, M. P.; Michalak, A.; Ziegler, T. A Combined Charge and Energy Decomposition Scheme for Bond Analysis. J. Chem. Theory Comput. 2009, 5, 962-975.

76. Hubbard, J. L.; Lichtenberger, D. L. Vibrational Fine Structure in the Valence Ionizations of Transition Metal Hexacarbonyls: New Experimental Indication of Metal-to-Carbonyl .Pi. Bonding. J. Am. Chem. Soc. 1982, 104, 2132-2138.

77. Higginson, B. R.; Lloyd, D. R.; Burroughs, P.; Gibson, D. M.; Orchard, A. F. Photoelectron Studies of Metal Carbonyls. Part 2.-the Valence Region Photoelectron Spectra of the Group Via Hexacarbonyls. J. Chem. Soc. Perk. Trans. 2 1973, 69, 1659-1668.

78. Fukuda, R.; Hayaki, S.; Nakatsuji, H. Valence Ionization Spectra of Group Six Metal Hexacarbonyls Studied by the Symmetry-Adapted Cluster-Configuration Interaction Method. J. Chem. Phys. 2009, 131, 174303.

79. Bayse, C. A.; Ortwine, K. N. Calculation of Photoelectron Spectra of Molybdenum and Tungsten Complexes Using Green's Functions Methods. J. Phys. Chem. A 2007, 111, 78417847.

80. Chen, Y.-J.; Liao, C.-L.; Ng, C. Y. A Molecular Beam Photoionization Mass Spectrometric Study of $\mathrm{Cr}(\mathrm{Co})_{6}, \mathrm{Mo}(\mathrm{Co})_{6}$, and $\mathrm{W}(\mathrm{Co})_{6 .}$. J. Chem. Phys. 1997, 107, 4527-4536. 
81. Garner Iii, E. B.; Arduengo Iii, A. J.; Streubel, R.; Dixon, D. A. Electronic Structure Predictions of the Properties of Non-Innocent P-Ligands in Group 6b Transition Metal Complexes. Dalton Trans. 2014, 43, 2069-2078.

82. Kendall, A. J.; Zakharov, L. N.; Tyler, D. R. Steric and Electronic Influences of BuchwaldType Alkyl-Johnphos Ligands. Inorg. Chem. 2016, 55, 3079-3090.

83. Gatineau, D.; Lesage, D.; Clavier, H.; Dossmann, H.; Chan, C. H.; Milet, A.; Memboeuf, A.; Cole, R. B.; Gimbert, Y. Bond Dissociation Energies of Carbonyl Gold Complexes: A New Descriptor of Ligand Effects in Gold(I) Complexes? Dalton Trans. 2018, 47, 15497 15505.

84. Orpen, A. G.; Connelly, N. G. Structural Systematics: The Role of P-A .Sigma.* Orbitals in Metal-Phosphorus .Pi.-Bonding in Redox-Related Pairs of M-Pa ${ }_{3}$ Complexes $(\mathrm{a}=\mathrm{R}$, $\mathrm{Ar}$, or; $\mathrm{R}=$ Alkyl). Organometallics 1990, 9, 1206-1210.

85. Yarbrough, L. W.; Hall, M. B. Photoelectron Spectra of Substituted Chromium, Molybdenum, and Tungsten Pentacarbonyls. Relative .Pi.-Acceptor And .Sigma.-Donor Properties of Various Phosphorus Ligands. Inorg. Chem. 1978, 17, 2269-2275.

86. Note also that on the cited PES, the intensity of the signal decreases down to zero between the two bands whereas our SPES presents an ion intensity different from zero between ca 8.0 and $9.2 \mathrm{eV}$. We attribute this difference to autoionization occurring in our experiments in contrast to high-energy photon absorption experiments which are known to show only direct ionization processes, see T. Baer, Annu. Rev. Phys. Chem., 1989, 40, 637-669.

87. Wada, Y.; Kiser, R. W. A Mass Spectrometric Study of Some Alkyl-Substituted Phosphines. J. Phys. Chem. 1964, 68, 2290-2295.

88. Frenking, G.; Fröhlich, N. The Nature of the Bonding in Transition-Metal Compounds. Chem. Rev. 2000, 100, 717-774.

89. Frenking, G.; Wichmann, K.; Fröhlich, N.; Grobe, J.; Golla, W.; Van, D. L.; Krebs, B.; Läge, M. Nature of the Metal-Ligand Bond in $\mathrm{M}(\mathrm{Co})_{5} \mathrm{px}_{3}$ Complexes $(\mathrm{M}=\mathrm{Cr}, \mathrm{Mo}, \mathrm{W} ; \mathrm{X}=\mathrm{H}$, $\mathrm{Me}, \mathrm{F}, \mathrm{Cl})$ : Synthesis, Molecular Structure, and Quantum-Chemical Calculations. Organometallics 2002, 21, 2921-2930.

90. Tolman, C. A. Electron Donor-Acceptor Properties of Phosphorus Ligands. Substituent Additivity. J. Am. Chem. Soc. 1970, 92, 2953-2956.

91. Amatore, C.; Carre, E.; Jutand, A.; M'Barki, M. A. Rates and Mechanism of the Formation of Zerovalent Palladium Complexes from Mixtures of $\mathrm{Pd}(\mathrm{Oac})_{2}$ and Tertiary Phosphines and Their Reactivity in Oxidative Additions. Organometallics 1995, 14, 1818-1826.

92. Ikuta, S.; Kebarle, P.; Bancroft, G. M.; Chan, T.; Puddephatt, R. J. Basicities of Methyl-, Methylphenyl-, and Phenylphosphines in the Gas Phase. J. Am. Chem. Soc. 1982, 104, 58995902.

93. Ganguly, S.; Ghosh, A. Seven Clues to Ligand Noninnocence: The Metallocorrole Paradigm. Acc. Chem. Res. 2019, 52, 2003-2014.

94. Jørgensen, C. K. Differences between the Four Halide Ligands, and Discussion Remarks on Trigonal-Bipyramidal Complexes, on Oxidation States, and on Diagonal Elements of OneElectron Energy. Coord. Chem. Rev. 1966, 1, 164-178.

95. Moloy, K. G.; Petersen, J. L. N-Pyrrolyl Phosphines: An Unexploited Class of Phosphine Ligands with Exceptional П-Acceptor Character. J. Am. Chem. Soc. 1995, 117, 7696-7710.

96. Politzer, P.; Murray, J. S.; Bulat, F. A. Average Local Ionization Energy: A Review. J. Mol. Model. 2010, 16, 1731-1742. 


\section{TOC Graphic}

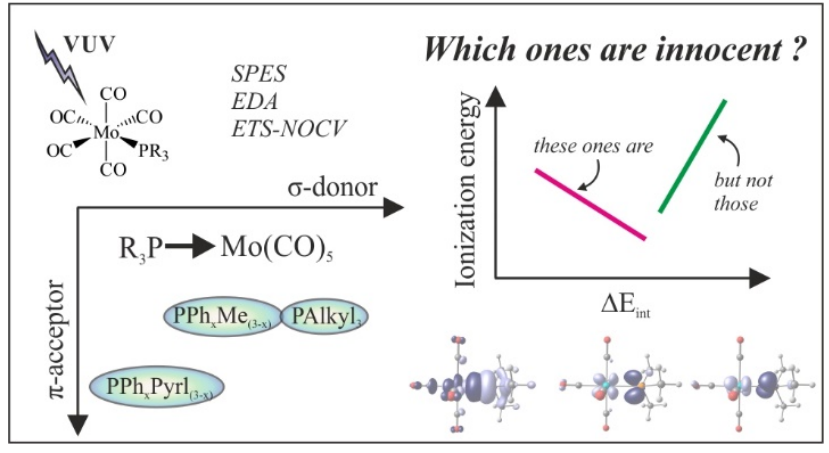

